\title{
Tracking the maturity of industry 4.0: the perspective of a real scenario
}

\author{
Vítor Alcácer $^{1,2,3,4}$ (D) Carolina Rodrigues ${ }^{1} \cdot$ Helena Carvalho ${ }^{1,2} \cdot$ Virgilio Cruz-Machado $^{1,2}$
}

Received: 2 February 2021 / Accepted: 24 June 2021 / Published online: 6 July 2021

(C) The Author(s), under exclusive licence to Springer-Verlag London Ltd., part of Springer Nature 2021

\begin{abstract}
To track industry 4.0 status, readiness models are used to analyze the state of industry 4.0 technologies' implementation, allowing the quantification and qualification of its readiness level considering different dimensions. Not all companies are adopting these new technologies with the same ease and with the same pace. There are companies unable to blend the industry 4.0 with their business models, leading to a lack of a correct self-assessment on understanding the reached readiness level. Into this purpose, it is important to understand how companies are facing the digital transformation challenges, what is their perception about the enabling technologies towards the industry 4.0 , assess the industry 4.0 ' readiness so far, and what are their perception of the barriers to the adoption of these technologies. This paper aims to assess the industry 4.0 ' readiness level of companies and discuss the perception of companies about the barriers on the adoption of industry 4.0 with the reached readiness level of companies. New barriers are also brought for discussion on academic community. To this end, empirical data was collected on a sample of 15 companies belonging to an important industrial cluster located in Portugal.
\end{abstract}

Keywords Industry $4.0 \cdot$ Readiness models $\cdot$ Readiness level $\cdot$ Implementation barriers $\cdot$ Company perception

\section{Introduction}

High energy costs, constrains on the acquisition of raw materials and qualified workforce, aligned to a weak internal demand, regulatory and administrative rigid processes, labor markets, low investment in research, development, and innovation, have tended on shifting the industrial sector to developing countries. Therefore, it is well known the importance of increasing the competitiveness on the manufacturing environment for the survival of each company. This new vision is

Vítor Alcácer

vitor.alcacer@estsetubal.ips.pt

1 Department of Mechanical and Industrial Engineering, Faculty of Science and Technology, Universidade Nova de Lisboa, Lisboa, Portugal

2 UNIDEMI, Department of Industrial and Mechanical Engineering, Faculty of Science and Technology, Universidade Nova de Lisboa, Lisboa, Portugal

3 Department of Mechanical Engineering, ESTSetúbal, Instituto Politécnico de Setúbal, Setúbal, Portugal

4 CDP2T, ESTSetúbal, Instituto Politécnico de Setúbal, Setúbal, Portugal enabling companies to look at the real value-added that can be created by themselves. Companies that in recent past followed the trend to relocate activities looking for low-cost labor are now pathing to recover their competitiveness.

Germany played a key rule on this paradigm shifting, launching public and private initiatives to maintaining and promoting its importance as a "forerunner" on the industry [1]. Industry 4.0 (I4.0) concept was first appeared in a German government article in November 2011 and was intitled as the "High-Tec strategy for 2020." The I4.0 term will appear again in Germany at Hannover industrial fair in 2013 and rapidly emerged as the German national strategy. As one of the most competitive global manufacturing industries, Germany developed a strategic plan to implement I4.0, helping on the transformation from de Industry 3.0 [2], with the heading of Industrie 4.0 [3].

The urgent need for the I4.0 implementation leads to a growing demand for this research topic in order to provide insights into the issues, challenges, and solutions for the design and implementation of the I4.0 [4]. Also, there is an overall acceptance among industries that I4.0 paradigm is an indispensable to shift manufacturing environments into a valuable asset and that there is no way to survive without it. This makes I4.0 a no longer "future trend" [4]. Up to date, I4.0 
is on the early stage of implementation in industry, human environment, and scientific research [5].

Not all industries are adopting these enabling technologies with the same ease and it is necessary to understand what the reasons behind these differences are. On the one hand, companies are unable to relate I4.0 with their business models and, on the other hand, companies are not able to self-assess in order to understand the reached readiness level. For companies to overcome uncertainty and discontent, it is necessary to use new tools to guide and support them [6]. Thus, to analyze the I4.0 different states, maturity and readiness models can be used. According to Schumacher et al. [6], a maturity model measures the maturation process and the readiness model measures how company is ready to the development process. The IMPULS model is an example of how to measure the I4.0 readiness with six dimensions (strategy and organization, smart factory, smart operations, smart products, data-driven services, and employees). These dimensions form the foundations to measure the I4.0 readiness having appropriate indicators.

As the implementation of I4.0 takes place at different pace around the world, it will be very important to understand what the barriers on I4.0 enabling technologies adoption are. The literature provides some studies not only regarding the maturity or readiness levels of I4.0 in companies [6-10], but also about the perception of the barriers associated with the implementation process [11-17].

I 4.0 is considered by some authors the fourth industrial revolution [18] and differs from previous because it was declared before it happened, and we are currently experiencing its evolution. In this way, the academic and industrial community have a great opportunity to be part of this revolution. This paper presents a study carried out on a region of great industrial importance in Portugal allowing the possibility to compare it with other studies in other regions and/or countries.

The surveyed companies bring to this paper the understanding on how they are facing the digital transformation and which are the main barriers to the technologies' adoption. Empirical data was collected using a survey to operationalize the IMPULS model and assess the companies' readiness level, in addition to semi-structured interviews with managers bring what are the companies' perceptions of the barriers' importance on the adoption of these enabling technologies. Through this study, it is also intended to bring to the scientific community new barriers on I4.0 enabling technologies adoption that, to the best of our knowledge, have not yet been identified in previous studies.

The rest of this paper is organized as follows: section 2 presents a brief overview over the enabling technologies to reach the I4.0 environment achieving the smart factory, introduces maturity and readiness models to measure the I4.0 status and barriers on the I4.0 enabling technologies adoption; section 3 exposes the research methodology followed on this paper; section 4 presents the results; section 5 provides a discussion on the results; and section 6 outlines the conclusions, the research limitations, and ongoing research.

\section{The path leading to the smart factory}

The first industrial revolution started after the introduction of mechanical manufacturing factories on the second half of the eighteen century [19]. Steam engines were gradually inserted on the production sector, then on the transport sector, and, finally, on energy production. This change was slow and took decades [20]. Since 1870, with the electrification and division of labor, the second revolution began [19]. This revolution began on the USA with the rapid expansion of industries, with new factories linked together and to a central power plant. It was during this revolution that Henry Ford developed the manufacturing system without interruption at the Detroit auto plant. The line operators were semi-qualified, and the parts produced were standardized, that is, it was a type of mass production [20].

The third revolution, also called the digital revolution, originated from electronic advances and computer technologies in 1970, which provided production automation increase [19]. Traditional industries based on oil, fossil fuels, and mass production could no longer be considered a complete solution to economic or social problems and, therefore, a cluster of innovative communication and energy technologies was created [20]. Figure 1 shows industrial progress from a historical perspective.

Currently, the fourth industrial revolution also coined by I4.0 aims to achieve higher level of automatization supporting a higher level of operational productivity and efficiency [21, $22]$, connecting the physical world to the virtual world [23, 24], and bringing into the traditional industry computerization and inter-connection [25]. Several authors, e.g., [21, 26, 27] assumed I4.0 as Cyber-Physical production, with its foundation on knowledge integration and heteronomous data using big data (BD) and advanced technologies such as Internet of Things (IoT) and Services (IoS), cybersecurity (CS), cloud computing (CC), and intelligent robotics [21, 22, 24].

The framework of the I4.0 is the development of the smart factory [22, 23, 26-30]. Gilchrist [30] assumed in conceptual terms that the Cyber-Physical Systems (CPS) are the heart of the I4.0. Adding to this vision, Hofmann and Rüsch [1] assumed the smart factory's main components as CPS, IoT, and IoS. These components built the decentralized concept for the production system with a social network connecting resources, machines, and humans [1]. When a smart factory uses cloudbased manufacturing, CPS and IoT, it converges to IoS to create, publish, and share manufacturing processes on a form of services that can be supplied by virtual enterprises [31].

The fundamental aspect in this new generation of smart factories is the integration within different levels: the vertical integration occurs inside the smart factory; the horizontal 


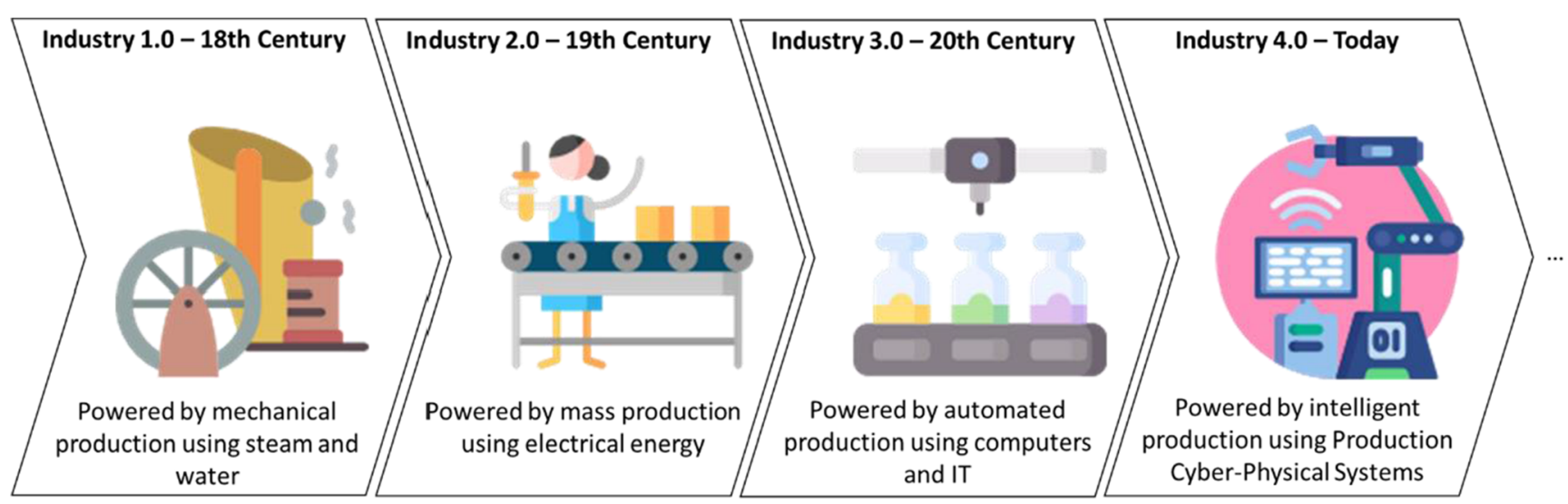

Fig. 1 Industrial progress from a historical perspective

integration occurs in the smart factory value chain; and end-toend integration across several smart factories, allowing the endto-end systems integration across the entire value chain [32].

Figure 2 shows the approach of I4.0 for manufacturing systems based on the smart factory concept with several enabling technologies and components such as IoT, IoS, the systems integration, and Cyber-Physical Production System (CPPS) composed by several CPS connected on a network. Depending on the purpose, the CPS component can use the key enabling technologies such as IoT, BD, CC, CS, horizontal and vertical integration, additive manufacturing (AM), augmented reality (AR), autonomous robots, and simulation. This approach can be seen in detail on a literature review of Alcácer et al. [18].

The importance of I4.0 is clearly assumed around the world. The fourth industrial revolution is the essential path for the industrial sector competitiveness.

\subsection{Measuring with readiness models}

I4. 0 and its related concepts are a complex topic for researcher and practitioners. The I4.0 implementation process is context dependent, and it will be different for each company. Therefore, it is necessary to analyze each case to better define the company objectives. The need to measure the progress and success, as well as the need of comparisons with competitors, is part of the industrial environments. Thus, there is a need to use proper methodologies, models, and tools to evaluate the I4.0 adoption. Assessment tools have been developed by academia and practitioners aiming the self-assessment within analytical frameworks to evaluate conditions or analyze it on an interactive form with the framework developers [33]. Several authors proposed models to address guidance and support on strategies and operations regarding the I4.0 implementation. A model can be an assessment tool outcoming a formal

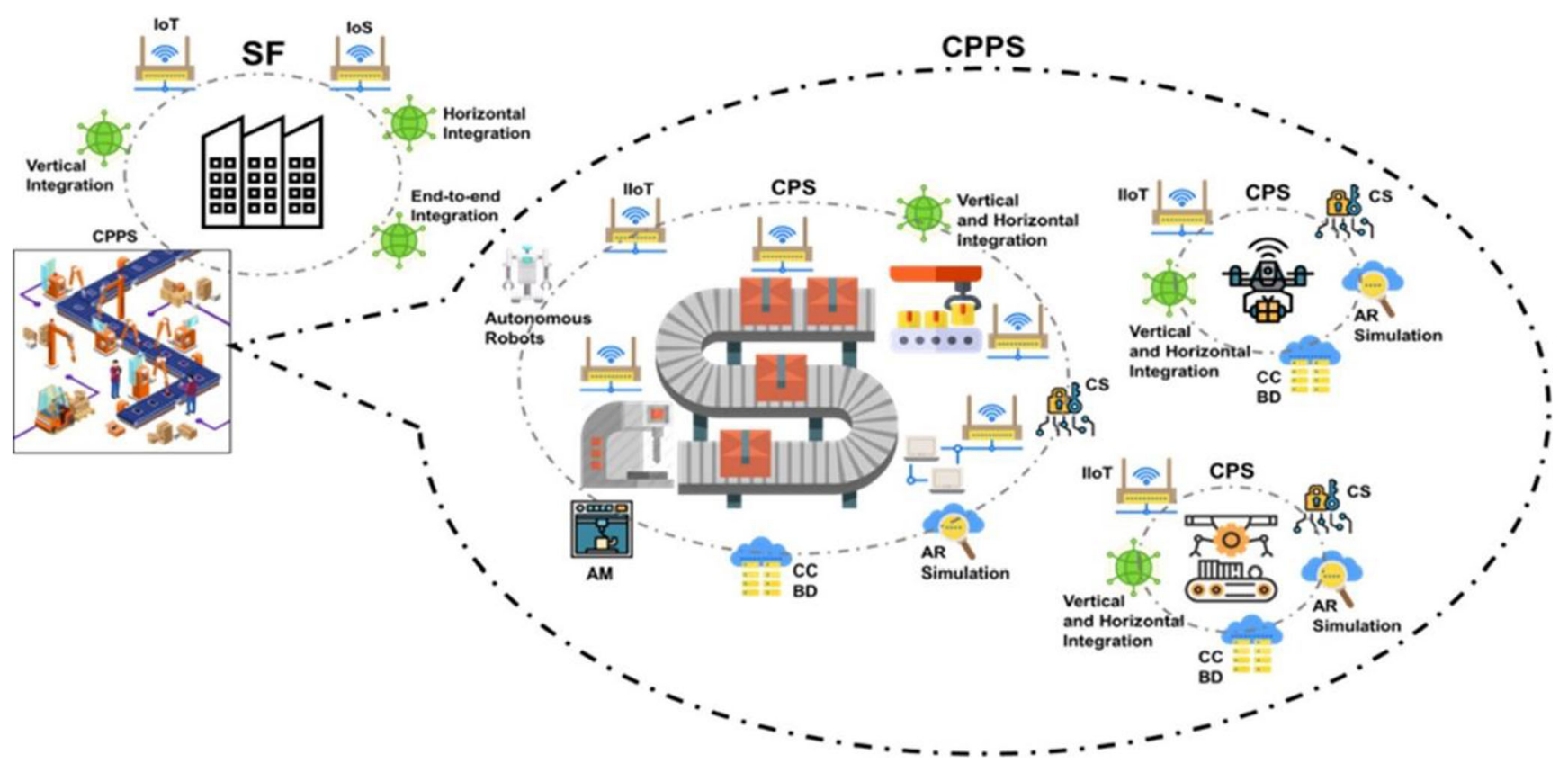

Fig. 2 The development of the SF concept [18] 
description of a given system, e.g., a manufacturing system, an organization, a manufacturing process, or a machine.

Depending on the representation definition and application purpose, models can be descriptive (reproduction of some reality aspects), explanatory (casual connection relations are investigated to better understand the reality), or predictive (efficient solution suggestions to face the future reality). At the end, all model approaches depict the current state of a given system [34]. Models also can be used as a comparative purpose, enabling maturity benchmarking across companies by similar practices within different industries [35]. Maturity models are a subcategory of models, arising on the software development field, used on an enterprise' assess the quality of implemented processes. The Capability Maturity Model Integration (CMMI) or Software Process Improvement and Capability dEtermination (SPICE) are examples of these models [36]. The maturity of a company is seen by Schumacher et al. [6] as the state of progression of internal and external conditions under the concepts of horizontal, vertical, and end-to-end engineering integration of I4.0 on manufacturing systems. Commonly, maturity models are used to measure the maturity of a given system regarding to a specific target state. Maturity models capture the "as-it-is state" [6].

Reaching a given maturity level is the foundation for the evolution to the next higher maturity level that can be planned and further implemented. Thus, the maturity models quantify activities and make them mature along time. To assess the maturity of a system using levels, maturity models are based on the idea of "state of being complete, prefect, or ready" and it can be addressed as qualitative or quantitative, in a discrete or continuous manner. As a close approach to maturity models, to assess readiness systems through levels, readiness models are based on the idea of "this is the starting point for," allowing the preparation for the development process of the measured given system. The "readiness" term induces a tendency for change in the given system. Readiness models intend to assess the state of the system before the engagement into the maturity transformation process [6]. Readiness models to assess I4.0 on companies are based on selfassessment mostly on the collection of information via internet surveys or via phone interviews [37].

Maturity and readiness models are mostly feeding by dimensions that represents thematic groups, constructed with numerical indicators, and extracted from the collected information from the given system [37]. Table 1 shows some I4.0 maturity and readiness models identified in the literature.

Both "Industrie 4.0 Maturity Index" [8] and "Maturity Model for Assessing Industry 4.0 Readiness and Maturity of Manufacturing Enterprises" [6] analyze more than six dimensions which makes them quite complete and may be a negative aspect as respondents need to have extensive knowledge about I4.0 technologies. "The Connected Enterprise Maturity Model" [9] and "Smart Manufacturing System Readiness Level (SMSRL)" [10] model have four dimensions that includes technical aspects of I4.0 implementing, such as information technologies, but it does not consider aspects related to human resources and the strategy adopted by the company.

After analyzing different maturity and readiness models in Table 1, the chosen model to be used on this research is the IMPULS [7] because it is based on well-defined dimensions, sub-dimensions, and their details, which greatly facilitates its application. Another reason for this choice was the existence of an online questionnaire of this model [38]. The questions from the IMPULS model can be adapted regarding to a particular country reality.

This model was funded by the IMPULS Foundation of the German Engineering Federation (VDMA) and developed by the IW Consult and the Institute for Industrial Management at

Table 1 Maturity and readiness models and respective dimensions

\begin{tabular}{|c|c|c|}
\hline Model & Dimensions & \\
\hline IMPULS Industrie 4.0 Readiness [7] & $\begin{array}{l}\text { - Strategy and organization } \\
\text { - Smart factory } \\
\text { - Smart operations }\end{array}$ & $\begin{array}{l}\text { - Smart products } \\
\text { - Data-driven services } \\
\text { - Employees }\end{array}$ \\
\hline Industrie 4.0 Maturity Index [8] & $\begin{array}{l}\text { - Computerization } \\
\text { - Connectivity } \\
\text { - Visibility }\end{array}$ & $\begin{array}{l}\text { - Transparency } \\
\text { - Predictability } \\
\text { - Adaptability }\end{array}$ \\
\hline $\begin{array}{l}\text { Maturity Model for Assessing Industry 4.0 Readiness } \\
\text { and Maturity of Manufacturing Enterprises [6] }\end{array}$ & $\begin{array}{l}\text { - Strategy } \\
\text { - Leadership } \\
\text { - Customers } \\
\text { - Products } \\
\text { - Operations }\end{array}$ & $\begin{array}{l}\text { - Culture } \\
\text { - People } \\
\text { - Governance } \\
\text { - Technology }\end{array}$ \\
\hline The Connected Enterprise Maturity Model [9] & $\begin{array}{l}\text { - Information infrastructure } \\
\text { - Controls and devices }\end{array}$ & $\begin{array}{l}\text { - Networks } \\
\text { - Security policies }\end{array}$ \\
\hline Smart Manufacturing System Readiness Level (SMSRL) [10] & $\begin{array}{l}\text { - Organizational maturity } \\
\text { - vInformation technology maturity }\end{array}$ & $\begin{array}{l}\text { - Performance maturity } \\
\text { - Information connectivity maturity }\end{array}$ \\
\hline
\end{tabular}


RWTH Aachen University. Other studies used this model, from dissertations [39-41] to scientific articles [42-44].

The IMPULS model consists of six dimensions, as well as the respective sub-dimensions (Table 2). The readiness score is calculated using a weighted arithmetic mean applying the weights proposed by [6] for each dimension. The readiness level on each dimension is attributed considering the minimum score of the respective sub-dimensions (evaluated on a scale from 1 to 5). For example, considering the "smart products" dimension, if a company reaches a score of 5 on "ICT add-on functionalities" sub-dimension, and a score of 1 on "use of data" sub-dimension, then readiness level of "smart products" dimension is 1 (minimum value among 1 and 5). The company's readiness score can be measured using a scale from 0 to 5 , as shown in Table 3. These six levels can be grouped into three categories as follows: (i) "newcomers" that describes companies that have adopted little or no I4.0 technologies; (ii) "learners" that characterizes the companies that have already taken the first actions to implement I4.0; and (iii) "leaders" that represents companies that have made various efforts to implement I4.0.

The I4.0 implementation is very important from a strategic point because it allows companies to develop entirely new business models. In the IMPULS model, the "smart factory" dimension describes an intelligent, interconnected factory that can communicate directly with the information technologies (IT) systems. This can be achieved through the placement of sensors across the factory, including machinery and systems, on critical data collection points. This process can generate large quantities of data (i.e., BD) which may be a problem if the IT infrastructure is underdeveloped. Another possible barrier related to this dimension is the high investment cost. The dimension "smart operations" focuses on the integration of systems as a key element for horizontal and vertical integration of the value chain, which provides the potential to improve productivity, flexibility, and quality. This dimension is highly dependent on the collection, analysis, and usage of data of the highest resolution possible which is why IT security is so important. Adding new features to "smart products" provides the data required for the data-driven services such as a predictive maintenance plan based on the usage level of the equipment. This dimension includes the information and communication technologies (ICT) add-on functionalities that allow the data collection and whether the data is used or analyzed. The dimension "data-driven services" represents the shifting from selling products to providing solutions. This change grants companies the opportunity to upgrade their business models and direct their attention to enhance the benefit to their customers. Nowadays, manufacturers are moving past selling machinery and are creating a new business with the maintenance of said machinery. The combination of products and services increases the added value to the final customer. All the above dimensions are focused on the technicalities of I4.0 but employees are the ones affected by the implementation of the I4.0 enabling technologies in their digital workplace. The dimension "employees" focuses on the skills and qualifications that companies require their employees to have.

\subsection{Barriers to $\mathbf{1 4 . 0}$ implementation}

Despite the advantages associated with the I4.0 implementation, companies may not use the appropriate technologies for their business; in addition, there are some barriers that hinder its implementation. A 2014 study carried out by the World Economic Forum [11] on the implementation of IoT concluded that, of all the identified barriers, the most important ones are the "lack of standards (difficult interoperability)" and "data security." Müller et al. [12] conducted a study on emerging technologies and their impact on business models. This study was carried out on Germany, in 2015, and focused on small and medium enterprises (SMEs). About two-thirds of participants consider that one of the most important barriers is the "high effort for coordination" to implement the enabling technologies. Some participants affirmed that the I4.0

Table 2 Relative dimension and sub-dimension weight. Adapted from [6]

\begin{tabular}{|c|c|c|c|}
\hline Dimension & Weight (\%) & Analyzed sub-dimensions & \\
\hline Strategy and organization & 25 & $\begin{array}{l}\text { - Degree of strategy implementation } \\
\text { - Definition of indicators }\end{array}$ & $\begin{array}{l}\text { - Investments } \\
\text { - Innovation management }\end{array}$ \\
\hline Smart factory & 14 & $\begin{array}{l}\text { - Equipment infrastructure (current) } \\
\text { - Equipment infrastructure (target) } \\
\text { - Digital modeling }\end{array}$ & $\begin{array}{l}\text { - Data collection } \\
\text { - Data usage } \\
\text { - IT systems }\end{array}$ \\
\hline Smart operations & 10 & $\begin{array}{l}\text { - System-integrated information sharing } \\
\text { - Autonomously guided workpieces } \\
\text { - Self-reacting processes }\end{array}$ & $\begin{array}{l}\text { - IT security } \\
\text { • Cloud usage }\end{array}$ \\
\hline Smart products & 19 & - ICT add-on functionalities & - Use of data \\
\hline Data-driven services & 14 & $\begin{array}{l}\text { - Data-driven services } \\
\text { - Share of revenue }\end{array}$ & - Level of data usage \\
\hline Employees & 18 & • Employee skills & \\
\hline
\end{tabular}


Table 3 Readiness levels and their description. Adapted from [6]

\begin{tabular}{|c|c|c|}
\hline \multicolumn{2}{|l|}{ Level } & \multirow{2}{*}{$\begin{array}{l}\text { Description } \\
\text { Companies that do not meet the necessary requirements and have done little to no planning for implementing I4.0. }\end{array}$} \\
\hline Newcomers & 0 (outsider) & \\
\hline & 1 (beginner) & $\begin{array}{l}\text { Companies that have pilot initiatives related to I } 4.0 \text { in some departments and investments in one of them. Just a few } \\
\text { of the production processes are supported through IT systems, and the existing equipment infrastructure only } \\
\text { partially fulfills the requirements for future integration and communications. IT security solutions are still in early } \\
\text { planning or starting to be implemented. }\end{array}$ \\
\hline Learners & 2 (intermediate) & $\begin{array}{l}\text { Companies that integrate I4.0 in their strategic orientation and already has a developed method with the appropriate } \\
\text { indicators to measure the implementation status. Some data is already being collected automatically and being } \\
\text { used to a limited extent. Information sharing is integrated within the company and the first steps to integrate } \\
\text { information sharing with business partners are being taken. Companies are already producing some items with } \\
\text { initial IT-based add-on functionalities. }\end{array}$ \\
\hline \multirow[t]{3}{*}{ Leaders } & 3 (experienced) & $\begin{array}{l}\text { Companies that already have a I } 4.0 \text { strategy developed with investments made in several departments. Data is being } \\
\text { collected automatically in key areas and the IT systems in production are connected using interfaces to support the } \\
\text { production processes. Information sharing is partially integrated to the system within the company and their } \\
\text { business partners. The needed IT security solutions are already enabled, and cloud computing solutions are } \\
\text { outlined to adapt to future expansion. Companies already provide items with IT-based add-on functionalities } \\
\text { which are the basis for data-driven services that not yet integrated with their customers. }\end{array}$ \\
\hline & 4 (expert) & $\begin{array}{l}\text { Companies that are already using an I } 4.0 \text { strategy and using the pertinent indicators to monitor its status. IT systems } \\
\text { support most of the production processes and the data collected from them is used for optimization. Companies } \\
\text { that are starting to adopt autonomously guided workpieces and self-reacting processes. The items provided by } \\
\text { these companies have IT-based add-on functionalities that combine data collection and targeted analysis during } \\
\text { the usage phase, which allows for data-driven services that feature direct integration between the customer and } \\
\text { producer. }\end{array}$ \\
\hline & 5 (top performer) & $\begin{array}{l}\text { Companies that have a well-defined I4.0 strategy and regularly monitor its implementation status. The requirements } \\
\text { for integration and system-integrated communications are already satisfied. Information sharing systems are } \\
\text { already fully integrated within the company and with its business partners. Exhaustive IT system support is } \\
\text { implemented in production and automatically collects all the important data and autonomously guided } \\
\text { workpieces, and self-reacting processes are already in use. Companies provide products with IT-based add-on } \\
\text { functionalities that supplies data for data-driven services such as product development, remote maintenance, and } \\
\text { sales support. }\end{array}$ \\
\hline
\end{tabular}

implementation implies high costs that their customers are not willing to pay. Despite these barriers, some participants mentioned that they consider the I4.0 technologies implementation for fear of losing customers to more technologically advanced competing companies.

Müller et al. [14] interviewed 68 German managers between May and June 2016. The study concluded that the most mentioned barriers were "lack of trust between business partners" due to the lack of "data security" and the "high effort for coordination."

Stentoft et al. [13] conducted a study on I4.0 barriers and drivers on Denmark in 2018. The study focused on SMEs and identified three groups of barriers on a literature review: "economic/financial," "skills/resources," and "high effort for coordination."

Li et al. [15], Beqqal and Azizi [16], and Yang et al. [30] focused on barriers associated with the implementation of certain technologies associated with I4.0. Li et al. [15] identified barriers related to the implementation of IoT, focusing mainly on more technical aspects such as the "lack of standards" or the "concern with the reliability of systems." Some barriers related to the implementation process were mentioned such as the "lack of an implementation methodology" and the "need to create new business models." Beqqal and Azizi [16] referred barriers related to technical aspects, as well as the legal aspect of data security in relation to radio frequency identification (RFID) technology. Yang et al. [17] confirm the results from [16], regarding $\mathrm{BD}$ and $\mathrm{CC}$, and they add the need for large investments as a relevant barrier.

Türkes et al. [45] conducted a study, in 2018, in Romania to understand the perspective of SMEs about I4.0 barriers and drivers, using a survey where respondents expressed whether they agreed or disagreed with a set of the barriers that companies could encounter when implementing the technologies associated with I4.0. The 176 companies that have participated were from areas such as automotive, pharmaceutical, chemical, insurance, or health. Six barriers were considered important by the respondents: "lack of clarification of economic benefits," "lack of technical knowledge," "insufficient workforce," "need for continuous formation," "lack of regulations and procedures," and "high effort for coordination."

Orzes et al. [46] propose 6 categories for I4.0 implementation barriers. Table 4 provides an overview of the studies available in the literature using the categories proposed by [46]. Most studies focus on SMEs and do not target a specific technology. The column "total" provides a counter that helps to identify the barriers most cited in the literature. 
Table 4 Main barriers to I4.0 implementation. Based on [46]

\begin{tabular}{|c|c|c|c|c|c|c|c|c|c|c|}
\hline Barriers & $\begin{array}{l}\text { Authors } \\
\text { Analyzed technology } \\
\text { Focus }\end{array}$ & $\begin{array}{l}{[13]} \\
\text { N/A } \\
\text { SME }\end{array}$ & $\begin{array}{l}{[45]} \\
\text { N/A } \\
\text { SME }\end{array}$ & $\begin{array}{l}{[11]} \\
\text { IoT } \\
\text { SME }\end{array}$ & $\begin{array}{l}{[12]} \\
\text { N/A } \\
\text { SME }\end{array}$ & $\begin{array}{l}{[14]} \\
\text { N/A } \\
\text { SME }\end{array}$ & $\begin{array}{l}{[15]} \\
\text { IoT } \\
\mathrm{N} / \\
\mathrm{A}\end{array}$ & $\begin{array}{l}{[16]} \\
\text { RFID } \\
\text { N/A }\end{array}$ & $\begin{array}{l}{[17]} \\
\mathrm{BD}+\mathrm{CC} \\
\text { N/A }\end{array}$ & Total \\
\hline \multirow[t]{2}{*}{ Economic/financial } & Need for large investments & $\mathrm{T}$ & & $\mathrm{E}$ & $\mathrm{E}$ & $\mathrm{E}$ & & & $\mathrm{T}$ & 5 \\
\hline & Lack of clarification of economic benefits & $\mathrm{T}$ & $\mathrm{T}$ & $\mathrm{E}$ & & & & & & 3 \\
\hline \multirow[t]{2}{*}{ Cultural } & Lack of support from top management & & & $\mathrm{E}$ & & & & & & 1 \\
\hline & Workers demotivation & & & & & $\mathrm{E}$ & & & & 1 \\
\hline \multirow[t]{4}{*}{ Skills/resources } & Lack of employees' skills & $\mathrm{T}$ & & $\mathrm{E}$ & $\mathrm{E}$ & & & & & 3 \\
\hline & Lack of technical knowledge & $\mathrm{T}$ & $\mathrm{T}$ & $\mathrm{E}$ & $\mathrm{E}$ & $\mathrm{E}$ & & & & 5 \\
\hline & Insufficient workforce & $\mathrm{T}$ & $\mathrm{T}$ & & & & & & & 2 \\
\hline & Need for continuous formation & $\mathrm{T}$ & $\mathrm{T}$ & & & & & & & 2 \\
\hline \multirow[t]{2}{*}{ Legal } & Lack of regulation and procedures & $\mathrm{T}$ & $\mathrm{T}$ & $\mathrm{E}$ & $\mathrm{E}$ & & $\mathrm{T}$ & & $\mathrm{T}$ & 6 \\
\hline & Concern about data security & $\mathrm{T}$ & & $\mathrm{E}$ & $\mathrm{E}$ & $\mathrm{E}$ & $\mathrm{T}$ & $\mathrm{T}$ & $\mathrm{T}$ & 7 \\
\hline \multirow[t]{5}{*}{ Technical } & Lack of standards (interoperability and compatibility) & & & $\mathrm{E}$ & & & $\mathrm{T}$ & $\mathrm{T}$ & $\mathrm{T}$ & 4 \\
\hline & Concern with the reliability of systems & & & & & & $\mathrm{T}$ & & $\mathrm{T}$ & 2 \\
\hline & Underdeveloped IT infrastructure & & & $\mathrm{E}$ & & & $\mathrm{T}$ & $\mathrm{T}$ & $\mathrm{T}$ & 4 \\
\hline & Data storage & & & & & & & $\mathrm{T}$ & $\mathrm{T}$ & 2 \\
\hline & Underdeveloped technologies & & & $\mathrm{E}$ & & & & & & 1 \\
\hline \multirow[t]{3}{*}{ Implementation process } & Need to create new business models & & & $\mathrm{E}$ & & $\mathrm{E}$ & $\mathrm{T}$ & & & 3 \\
\hline & Lack of an implementation methodology & & & & & & $\mathrm{T}$ & & & 1 \\
\hline & High effort for coordination & $\mathrm{T}$ & $\mathrm{T}$ & & $\mathrm{E}$ & $\mathrm{E}$ & & & & 4 \\
\hline
\end{tabular}

Note: $T$, theoretical; $E$, empirical; $N / A$, not applicable

\section{Research methodology}

The framed research questions established for this study are:

RQ1: What are the I4.0 readiness levels founded so far on an industrial cluster?

RQ2: What is the perception of the barriers' importance to implement 14.0?

To answer both research questions, this study adopts a twophase methodology:

- First phase - It was carried on a survey to measure the I4.0 readiness levels on an industrial cluster. The survey was elaborated according to the IMPULS model. The companies' responses were analyzed using an Excel document, coded to automatize the attribution of the readiness level for each dimension and respective sub-dimensions;
- Second phase - Semi-structured interviews were conducted to assess the perception that companies have about the barriers on the adoption of I4.0 enabling technologies. Based on the literature review, it was formulated an interview protocol (including a questionnaire) to better understand what the company's perception is regarding to each barrier.

\subsection{Survey methodology}

To answer to the first research question (RQ1), a survey was conducted. A survey is described as "a systematic method for gathering information from (a sample of) entities for the purposes of constructing quantitative descriptors of the attributes of the larger population of which the entities are members" [47]. The steps followed on this phase are as shown in Figure 3.

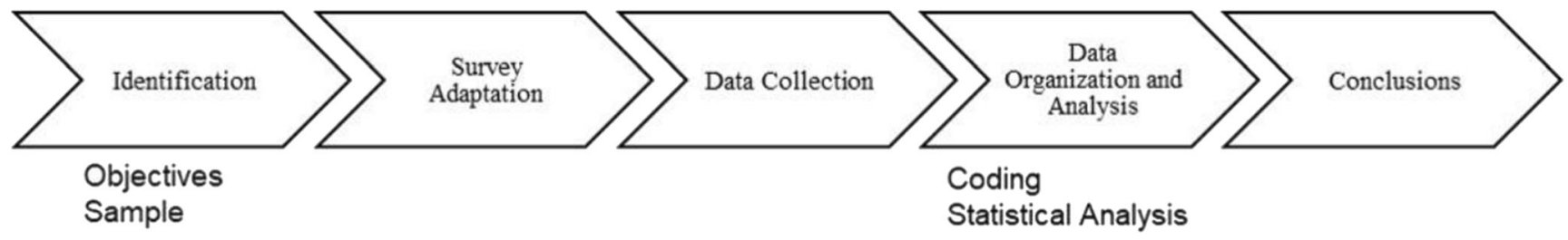

Fig. 3 Survey methodology steps 
The first step was the identification of the objectives and definition of the sample. This study is focused on companies located in a Portuguese industrial cluster, more specifically on Setubal peninsula, which has an area of $1421 \mathrm{~km}^{2}$ and covers nine counties, where 782,044 people live. There are 27,788 companies registered across the 9 counties on the Setubal peninsula.

According to Directório Empresas Portugal [48], companies on Setubal peninsula mainly have an activity area of "wholesale and retail trade, repair of motor vehicles and motorcycles." A company can have more than one activity area, one being the primary and the other the secondary; Table 5 does not make this distinction, since both are accounted for.

The target population considered on this study were companies associated to an industry association located in Setubal peninsula named as AISET - Associação da Indústria da Peninsula de Setúbal [49]. Currently, AISET is considered a national reference and an active voice not only on the region, but also in Portugal. Since December 2014, this association aims to combat the lack of representativeness of industrial companies on Setubal peninsula [49]. The choice to partnership with AISET was based on the fact that some associated companies operate together and form value chains, leading to the creation of synergies among themselves which leads to the development of the ecosystem itself. The partnership with AISET on this study also enhances the possibility of comparing the readiness levels between the companies involved on the same value chain.
AISET is an association with 55 very diverse members, from large companies (with more than 3500 employees) to micro-companies (with only two employees) [49]. The distribution of members, according to their activity area, is shown in Table 6 . The activity area of most companies is the manufacturing industry, followed by education area. These two activities represent more than half of AISET members.

This study makes use of a sample and therefore, there are associated errors present. One of them is the sampling error. This type of error is statistically well understood and is related to the sample size [50]. A sampling error can be summarized as the fact that the chosen sample is not representative of the population. To decrease this error, it is necessary to randomly choose a sample as large as possible [51]. The measurement error occurs when the answers are imprecise and differ from the "true" value [50]. Finally, the nonresponse error, which, as the name implies, refers to the lack of response from some respondents [50]. To reduce this error, follow-up procedures can be scheduled or elaborate an intuitive questionnaire with a simple design [51].

On the second step, the "Mapping the Adoption of Industry 4.0 Technologies in the Setubal Peninsula" survey was elaborated, as a part of the "Driving Industry 4.0" project [52]. The survey was operationalized using the LimeSurvey software, with the questions from the IMPULS model.

The next step was collecting survey data. The survey was launched on the beginning of July 2020. Under the
Table 5 Activity area of companies on Setubal peninsula. Adapted from [48]

\begin{tabular}{ll}
\hline Activity area & $\%$ \\
\hline Wholesale and retail trade, repair of motor vehicles and motorcycles & 31.0 \\
Construction & 15.6 \\
Accommodation, catering, and similar & 9.5 \\
Manufacturing industries & 8.4 \\
Other service activities & 5.2 \\
Consulting, scientific, technical, and similar activities & 4.9 \\
Real estate activities & 4.2 \\
Agriculture, animal production, hunting, forestry, and fishing & 4.1 \\
Administrative and support service activities & 4.0 \\
Transport and storage & 3.0 \\
Human health and social support activities & 2.8 \\
Artistic, show, sports, and recreational activities & 2.1 \\
Information and communication activities & 1.7 \\
Financial and insurance activities & 1.7 \\
Education & 1.2 \\
Water collection, treatment, and distribution; sanitation, waste management, and remediation & 0.20 \\
Public administration and defense; social security & 0.14 \\
Extractive industries & 0.11 \\
Electricity, gas, steam, hot and cold water, and cold air & 0.055 \\
Activities of international organizations and other extraterritorial institutions & 0.0024 \\
Activities of households employing domestic staff and production activities of households for own use & 0.0012 \\
\hline
\end{tabular}


Table 6 Activity area of AISET member companies [49]

\begin{tabular}{ll}
\hline Activity area & $\%$ \\
\hline Manufacturing industries & 43.6 \\
Education & 10.9 \\
Water collection, treatment, and distribution; & 9.1 \\
$\quad$ sanitation, waste management, and remediation & \\
Wholesale and retail trade, repair of motor & 9.1 \\
$\quad$ vehicles and motorcycles & \\
Transulting, scientific, technical, and similar activities & 9.1 \\
Real estate activities & 7.3 \\
Administrative and support service activities & 3.6 \\
Information communication activities & 1.8 \\
Construction & 1.8 \\
Other service activities & 1.8 \\
\hline
\end{tabular}

General Data Protection Regulation (GDPR), AISET contacted its associates to identify which ones would be interested on participating on this study. As companies are protected by GDPR, it is not possible to identify them, having been assigned a number to each one. After this collection, 17 companies accepted to participate in the study, representing $30.9 \%$ of the associates.

Due to the COVID-19 pandemic, the first contact was made by email and only two companies have responded to entire survey. Since the response rate was insufficient, it was necessary to send the survey a second time. This second contact was made on the first half of September 2020. Some companies were contacted by email, but the phone contact was more efficient in order to request the survey conclusion. On this phase, 13 responses were collected, adding to a total of 15 and, thus obtaining a response rate of $88.2 \%$. After compiling all the answers, it was necessary to organize and analyze them. For this purpose, an Excel document was coded to carry out a statistical analysis. Based on this document, conclusions were drawn on the final step.

\subsection{Identification of barriers to 14.0 implementation}

To answer the second research question established for this study (RQ2), it was used a methodology similar to [45]. To generalize the obtained conclusions, it was necessary to choose more than one company to interview. The selection of cases represents an opportunity, allowing a better understanding of the cases and provides a holistic view of them [53]. It is necessary to consider the available resources to expand the investigation and cover as many cases as possible. The choice of a small number of case studies may impact the quality of the results obtained and the ability to generalize them, as an unrepresentative sample of case studies can result in unreliable conclusions [53].
In this study, the criteria for the company's selection were the polar type method, where companies that were on extreme and opposite situations are selected. In this paper research setting, companies that obtained a maximum and minimum readiness level on the first research step were selected, i.e., two companies were selected from each extreme. This approach makes possible to identify contrasting patterns [54]. This selection method was used due to the limited number of responses to better represent the population [55].

An interview protocol is elaborated including a questionnaire with the most cited barriers in Table 4. Before the interview took place, the resulting questionnaire was sent to the four companies by email, on the 23rd of October 2020. Due to the COVID-19 pandemic situation, it was not possible to schedule in-person meetings, the semi-structured interviews were done by phone. The mentioned barriers on the questionnaire were discussed during these interviews to understand which ones were considered most important and whether there were any other relevant barriers beyond those already listed. Each interview lasted approximately $30 \mathrm{~min}$.

\section{Results}

All readiness levels mentioned in this section are between 0 and 5, using the criteria defined in Table 3 . The best readiness level for a company is readiness level 5 , which represents a "top performer" company and belongs to "leaders" category, which also includes readiness level 3 as "experienced" and readiness level 4 as "expert" companies. A company classified as readiness level 2 is called "intermediate" and belongs to "learners" category. Finally, companies that reach readiness level 0 as "outsider" or readiness level 1 as "beginner" belong to the "newcomers" category.

The last part of this section is focused on the impacts of the current pandemic scenario. Some companies took it as a chance for implementing new technologies in order to ease remote working and others viewed it as a barrier to new investments due to the decrease of its turnover.

\subsection{Survey answers}

The online survey was sent and analyzed according to the IMPULS model methodology proposed by Lichtblau et al. [7]. The survey was completed autonomously by the respondents; therefore, the answers translated a company's self-assessment. Assistance was offered to the respondents to decrease the possibility of answers that deviated from the companies' reality. Despite this, there is still a possibility that the answers do not depict their reality due to lack of knowledge of the I4.0 thematic. To assure data confidentiality and anonymous, each company participating into the survey was numbered from 1 to 17 . 
Fig. 4 Characterization of companies according to their business volume

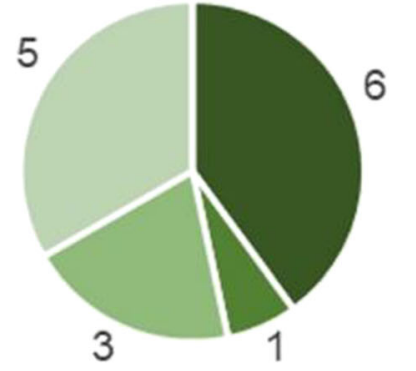

- Less than 2 million euros

- Between 2 and 10 million euros

= Between 10 and 50 million euros

= More than 50 million euros
Companies 3 and 14 did not answer to this survey; therefore, they will not be referred on this analysis.

\subsubsection{Characterization of companies}

The 15 surveyed companies can be classified according to the number of employees and business volume, and then classified as micro, small, medium, or large companies. The companies' characterization regarding their business volume is represented in Figure 4. According to the established parameters in Table 7, only one company is defined as micro, four companies as medium and large, and small companies are in equal number, five of each. This distribution can be seen in Figure 5.

The companies in sample were also classified according with the principal economic activity. The bigger activity area of respondents belongs to the manufacturing industry, as can be seen in Figure 6.

\subsubsection{Overall sample results}

The answers obtained through the survey can be grouped according to the readiness level for each dimension, as shown in Table 8 . Figure 7 provides another data visualization, allowing to quickly identify the readiness level for the IMPULS six dimensions.

The "employees" dimension is the only one in which the surveyed companies presented a readiness equal or higher than 2 "intermediate." Only two dimensions, "smart products" and "employees," have companies with the maximum readiness level 5 "top performer." Table 8 shows that on four out of six analyzed dimensions, there are no companies reaching the highest readiness level: "strategy and organization," "smart factory," "smart operations," and "data-driven services."

Table 9 shows the average readiness level obtained on each sub-dimension. The lowest average was readiness level is 0.6 ; it was obtained on "level of data usage" sub-dimension on "data-driven services." The highest average was readiness level 4.2; it was obtained on "cloud usage" sub-dimension which belongs to "smart operations". Each dimension will be analyzed in more detailed on next subsections.

Through the analysis of Figure 8, it is possible to conclude that only less than $20 \%$ of companies do not use any technology from those mentioned on the survey and more than $70 \%$ already use sensors, which is the most used technology.

Depending on the product or service type offered by each company, it may be difficult to introduce certain I4.0 technologies, which may negatively impact their readiness score. For illustration purposed, considering the "smart factory" dimension, there are companies who obtained the minimum level on a particular sub-dimension because of their context. For example, a company that manufactures electronic-based products and equipment will find it easier to use digital modeling than a company dedicated to transportation and storage. According to Lichtblau et al. [7], the "smart factory" dimension has a weight of $14 \%$ on the final readiness score. If a company reaches the maximum readiness level on all other five dimensions and the minimum readiness level on "smart factory" (readiness level 1), then the company overall
Table 7 Criteria to characterize the dimension of companies

\begin{tabular}{lll}
\hline Number of employees & Business volume & Classification \\
\hline Up to 9 employees & Less than 2 million euros & Micro \\
Between 10 and 49 employees & Between 2 and 10 million euros & Small \\
Between 10 and 49 employees & Between 2 and 10 million euros & Small \\
Between 50 and 249 employees & Between 10 and 50 million euros & Medium \\
Between 50 and 249 employees & Between 2 and 10 million euros & Medium \\
Between 50 and 249 employees & More than 50 million euros & Large \\
250 employees or more & More than 50 million euros & Large \\
\hline
\end{tabular}




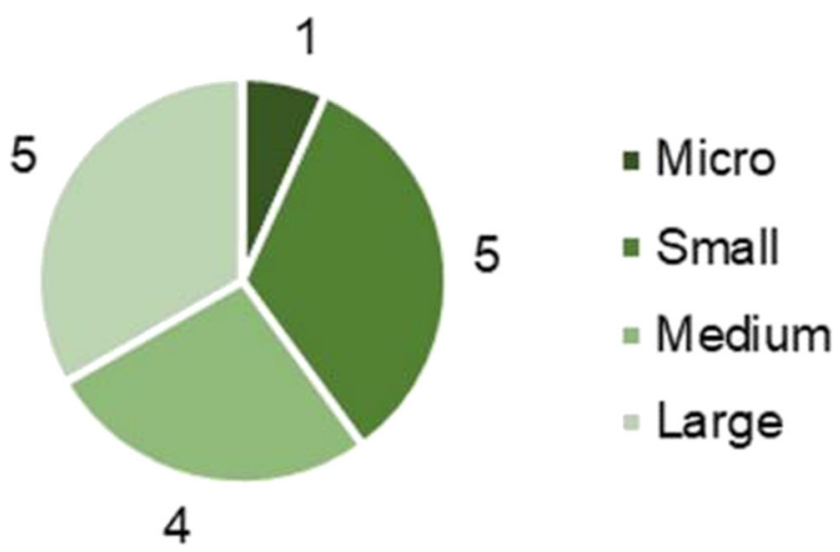

Fig. 5 Characterization of companies according to the number of employees

readiness score will be given by of 4.44 , which translates to a final readiness score of 4 . According to Table 2, the IMPULS model readiness overall score has the criteria of the weighted six dimensions as follows: strategy and organization (25\%), smart factory (14\%), smart operations (10\%), smart products (19\%), data-driven services (14\%), and employees (18\%).

As described previously, companies can be grouped according to their readiness score into three categories. Companies categorized as "newcomers" (readiness score 0 and 1) represent $53.3 \%$ of the sample. About $26.7 \%$ of the sample belongs to "learners" category (readiness score 2 ) and the remaining $20 \%$ belong to "leaders" group (readiness score 3, 4, and 5). On "leaders" group, there are no companies with readiness level 4 (expert) or readiness score 5 (top performer), with the maximum readiness score being seen by companies as a long-term objective. By looking at Figure 9, it can be seen that more than half of the companies $(60 \%)$ obtained a readiness score below the average. There is a discrepancy of 2.71 between the readiness score of the company with the highest and lowest rating, with no apparent relationship between the rating and the size or activity area of the companies.
On average, companies reached a readiness score of 1.74 , which is a relatively low readiness score, despite being higher when compared with the readiness score obtained by Lichtblau et al. [7]. This difference can be explained by the characterization of the chosen sample of companies. Lichtblau et al. [7] conducted the study exclusively with companies with more than twenty employees located across Germany, focusing on manufacturing companies. The chosen sample on this study includes companies of different sizes and does not include exclusively companies on manufacturing sector.

Table 10 provides the details of the two companies with highest and lowest readiness levels. Figure 10 shows for this set of companies, the readiness level achieved in the different sub-dimensions and its comparison with sample' average level.

\subsubsection{Analysis of "strategy and organization" dimension}

The average readiness level for "strategy and organization" dimension was 1.5 . Thus, $46.7 \%$ of companies obtained a readiness level 0 , which means that they are considered "outsiders" because they do not reach the necessary requirements. On this dimension, no company reached readiness level 5.

One aspect that may contribute to such a low average readiness level is the fact that almost half of the respondents (46.7\%) have no I4.0 strategy implemented or under development. As shown in Table 9, the sub-dimension that has the lowest average level is "degree of strategy implementation," and the sub-dimension with the highest average level was "innovation management," on which the readiness level most often obtained by companies was readiness level 3, which means that there is only innovation management in one company area.

The three companies that obtained the highest readiness level on this dimension are companies 5, 8, and 17 . Companies 5 and 8 have a similar characterization, both belong to the manufacturing sector and large companies, with a

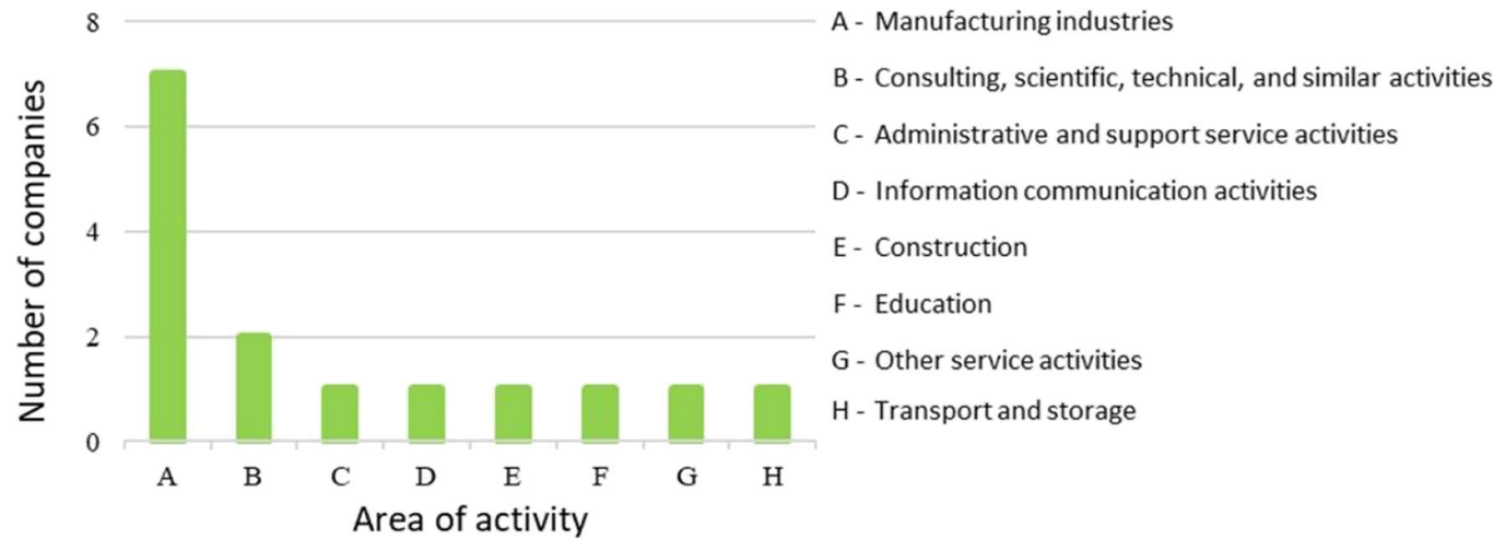

Fig. 6 Characterization of companies according to their activity area 
Table 8 Number of companies in each readiness level according to the dimensions

\begin{tabular}{|c|c|c|c|c|c|c|c|}
\hline \multicolumn{2}{|c|}{ Readiness level } & \multirow{2}{*}{$\begin{array}{l}\text { Strategy and organization } \\
7\end{array}$} & \multirow{2}{*}{$\begin{array}{l}\text { Smart factory } \\
8\end{array}$} & \multirow{2}{*}{$\frac{\text { Smart operations }}{1}$} & \multirow{2}{*}{$\begin{array}{l}\text { Smart products } \\
9\end{array}$} & \multirow{2}{*}{$\begin{array}{l}\text { Data-driven services } \\
11\end{array}$} & \multirow{2}{*}{$\begin{array}{l}\text { Employees } \\
0\end{array}$} \\
\hline 0 & Outsider & & & & & & \\
\hline 1 & Beginner & 2 & 5 & 2 & 3 & 1 & 0 \\
\hline 2 & Intermediate & 1 & 2 & 4 & 1 & 3 & 2 \\
\hline 3 & Experienced & 2 & 0 & 6 & 0 & 0 & 4 \\
\hline 4 & Expert & 3 & 0 & 2 & 0 & 0 & 8 \\
\hline 5 & Top performer & 0 & 0 & 0 & 2 & 0 & 1 \\
\hline
\end{tabular}

business volume of more than $€ 50$ million and more than 250 employees. Company 17 is a small company in the construction sector, a business volume of less than $€ 2$ million and a number of employees between 10 and 49 .

\subsubsection{Analysis of "smart factory" dimension}

On this dimension, companies obtained an average readiness level of 0.6 , with the most common value of readiness level 0 ( $53.3 \%$ of respondents), as can be seen in Table 8 . A company that has a readiness level 0 on this dimension means that it has not met the necessary requirements.

Table 9 shows that sub-dimension with the lowest average readiness level is "equipment infrastructures (target)," in which seven respondents obtained readiness level 0 , that is, $46.7 \%$ of the companies report their systems and machines cannot be updated. The sub-dimension with the highest average readiness level is "data collection," in which $40.0 \%$ of companies answered that they do not collect data from machines and processes.

The two companies that obtained the readiness level 2 on this dimension were companies 8 and 11. Company 8 is a large company and has an activity area of manufacturing industries. Company 11 is considered medium size and belongs to the activity area of consultancy, scientific, technical, and similar activities.

\subsubsection{Analysis of "smart operations" dimension}

On the "smart operations" dimension, companies in sample obtained an average readiness level 2 on the corresponded scale from level 0 to 5 . Only one company obtained readiness level 0 , most companies (40\%) obtaining readiness level 3 and none achieving readiness level 5 , as shown in Table 8 . A company at readiness level 3 is considered experienced and it can be said that there are initial solutions for $\mathrm{CC}$, data storage, and data analysis, it already has IT security solutions partially implemented, and there are some information sharing systems.

As it can be seen in Table 9, the sub-dimension where companies obtained, on average, a lower readiness level was "system-integrated information sharing," which means that these companies have integrated sharing information systems between departments on all areas and between customers and suppliers in more than five areas. The sub-dimension on
Fig. 7 Readiness level distribution on different dimensions

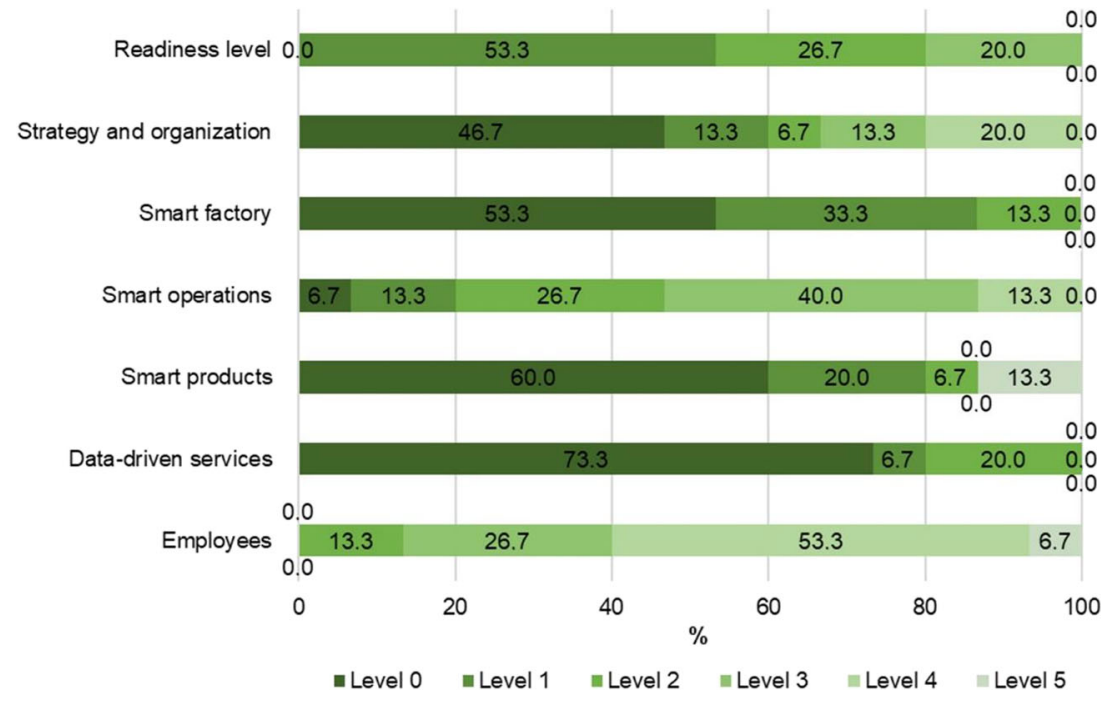


Table 9 Average readiness level on each sub-dimension

\begin{tabular}{lll}
\hline Dimension & Sub-dimension & Average level \\
\hline Strategy and organization & Degree of strategy implementation & 1.7 \\
& Definition of indicators & 2.8 \\
& Investment & 2.8 \\
& Innovation management & 3.4 \\
Smart factory & Equipment infrastructure (current) & 2.1 \\
& Equipment infrastructure (target) & 1.4 \\
& Digital modeling & 2.2 \\
& Data collection & 2.3 \\
Smart operations & Data usage & 1.8 \\
& IT systems & 1.7 \\
& System-integrated information sharing & 3.3 \\
Employees & Autonomously guided workpieces & 3.4 \\
& Self-reacting processes & 3.9 \\
Smart products & IT security & 4.1 \\
Data-driven services & Cloud usage & 4.2 \\
& ICT add-on functionalities & 1.7 \\
& Use of data & 2.1 \\
& Data-driven services & 0.9 \\
& Level of data usage & 0.6 \\
& Employee skills & 3.5 \\
\hline
\end{tabular}

which most companies obtained a higher average readiness level was "cloud usage," where only two companies do not use $\mathrm{CC}$, one of which is planning on starting to use it. On this sub-dimension, most respondents reached readiness level 4, stating that there is some use of CC services on the company.

Most companies $(80 \%)$ do not use autonomously guided workpieces, $53.3 \%$ do not have self-reacting processes, and $53.3 \%$ of the companies have implemented all IT security solutions mentioned on the survey.

Companies that obtained readiness level 4 on this dimension were the same ones that obtained the highest readiness level on the "smart factory" dimension (companies 8 and 11).

\subsubsection{Analysis of "smart products" dimension}

On the "smart products" dimension, companies obtained an average readiness level 1 on the corresponded scale from level
0 to 5 . As it can be seen in Table 8 , most companies $(60 \%)$ obtained a readiness level 0 , being placed on "outsider" category because they do not meet the necessary requirements.

As shown in Table 9, the sub-dimension on which companies reached the highest readiness level on average was "use of data." Despite having a higher level than the other subdimension (ICT add-on functionalities), it is still a low value due to the lack of data analyzed during the usage phase, being that ten companies $(66.7 \%)$ do not collect or analyze them, which represents a readiness level 1 on this sub-dimension.

The two companies that have reached the maximum readiness level on this dimension, companies 5 and 12, have different activity areas and sizes. Company 5 has already been described in section 4.1.3. Company 12 is considered small because it has between 10 and 49 employees and its business volume does not exceed $€ 2$ million. This company belongs to the information and communication activity area.
Fig. 8 Used technologies by surveyed companies

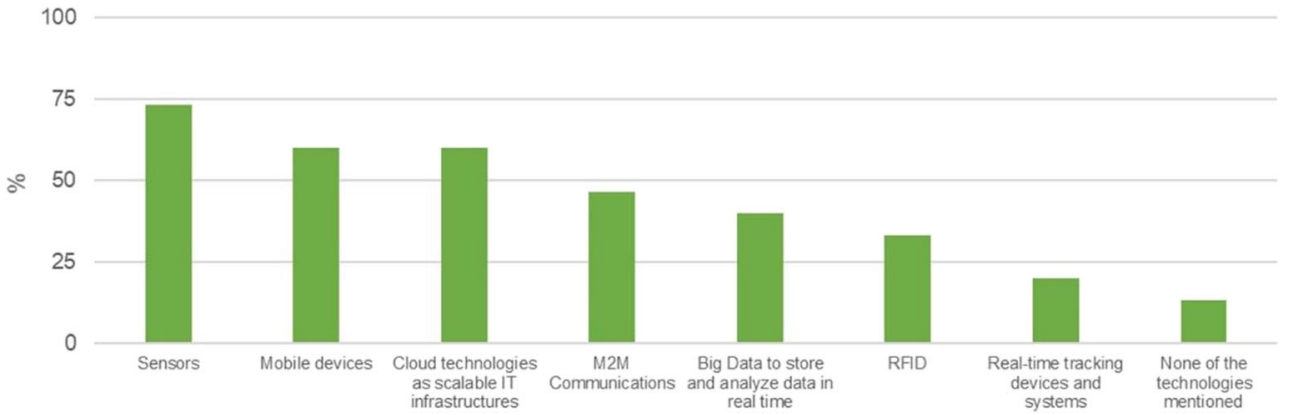


Fig. 9 Distribution of companies' readiness score and comparison with sample's average readiness score

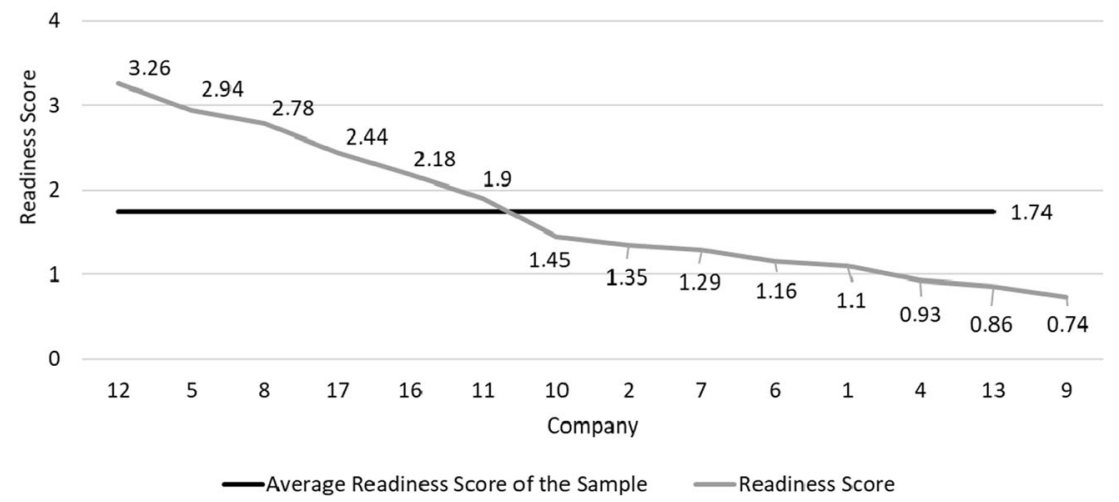

\subsubsection{Analysis of "data-driven services" dimension}

On the "data-driven services" dimension, companies obtained an average readiness level 0.5 on the corresponded scale from level 0 to 5 . As it can be seen in Table 8 , the most frequently readiness level assigned was readiness level 0 , which means that the companies under study do not meet the necessary requirements.

The most frequently assigned value on "data-driven services" sub-dimension was readiness level 0 , as shown in Table 9, which leads to a low average value. A company on readiness level 0 does not provide data-driven services, which may be due to their activity area. Some companies may integrate data-driven services in an easier way because of the product or service type they offer. For instance, a company that offers electronic-based products and equipment will find it easier to introduce a data-driven service than an ink manufacturing company.

Through the surveyed questions, it was not possible to obtain the readiness level of "share of revenues" subdimension; thus, this sub-dimension was not considered. On this study, it was not possible to apply directly the methodology proposed by the IMPULS model. According to the suppression of "share of revenues" sub-dimension, the "level of data usage" sub-dimension reached a maximum of readiness level 2. This limitation affects four companies that have a higher level on the other sub-dimension, as it can be seen in Table 11.
The maximum level reached on this dimension was readiness level 2 and only three companies $(8,12$, and 17) reached it, all of which were affected by the limitation described above. Throughout section 4.1, these companies were characterized. The only common factor is the size of companies 12 and 17 , both considered small.

\subsubsection{Analysis of "employees" dimension}

On the "employees" dimension, companies obtained an average readiness level of 3.5 on the corresponded scale from level 0 to 5 . This was the dimension that obtained the highest average readiness level which is justified by the fact that no company obtained a readiness level 1 or lower and the most frequent value was readiness level 4 , as Table 8 shows. The eight companies $(53.3 \%)$ on readiness level 4 fall into "expert" category which means that they consider that their employees have the adequate qualifications on most of relevant areas.

Only company 12 reached the maximum of readiness level 5 on this dimension.

\subsection{Results of identifying the barriers to I4.0 implementation}

Based on the surveyed companies' readiness level, the four companies represented in Figure 10 were selected to carry out the second phase of this study.

Table 10 Companies with highest and lowest readiness levels

\begin{tabular}{|c|c|c|c|c|c|c|c|}
\hline & Company & Activity area & Employees number & Business volume & Dimension & Readiness score & $\begin{array}{l}\text { Readiness } \\
\text { category }\end{array}$ \\
\hline Best performers & $\begin{array}{l}12 \\
5\end{array}$ & $\begin{array}{l}\text { Information and communication } \\
\text { Manufacturing }\end{array}$ & $\begin{array}{l}10 \text { to } 49 \\
<250\end{array}$ & $\begin{array}{l}<2 \text { million euros } \\
>50 \text { million euros }\end{array}$ & $\begin{array}{l}\text { Small } \\
\text { Large }\end{array}$ & $\begin{array}{l}3.26 \\
2.94\end{array}$ & Leaders \\
\hline Worst performers & $\begin{array}{l}13 \\
9\end{array}$ & $\begin{array}{l}\text { Manufacturing } \\
\text { Manufacturing }\end{array}$ & $\begin{array}{l}50 \text { to } 249 \\
10 \text { to } 49\end{array}$ & $\begin{array}{l}>50 \text { million euros } \\
<2 \text { million euros }\end{array}$ & $\begin{array}{l}\text { Large } \\
\text { Small }\end{array}$ & $\begin{array}{l}0.86 \\
0.55\end{array}$ & Newcomers \\
\hline
\end{tabular}


Table 11 Companies affected by the limitation imposed on "level of data usage" sub-dimension

\begin{tabular}{lll}
\hline Company & Data-driven services & Level of data usage \\
\hline 2 & 3 & 1 \\
8 & 3 & 2 \\
12 & 5 & 2 \\
17 & 3 & 2 \\
\hline
\end{tabular}

Based on the barriers to I4.0 implementation present in Table 4 and using the criteria described in section 2.2., it was elaborated a questionnaire to serve as guide during the semi-structured interviews. This questionnaire contained the barriers displayed in Table 12 and the respondents had to evaluate their importance by attributing a number between 1 and 5, meaning 1 being not important and 5 being extremely important. The overall perception of each barrier's importance was obtained by adding the importance values that each company attributed. The sum of the importance values is represented on the "total" column of Table 12.

Both companies with a lower readiness level considered that one of the most important barriers is "lack of support from top management." This barrier is not related to the size of these companies as one is large and the other small. Company 9 (small) also states that "lack of employees' skills" is a very important barrier, which is on agreement with the readiness level obtained on the dimension "employees" being lower than the average of the AISET associates. Company 13 considers "lack of employees' skills" an important barrier, despite having a higher readiness level than average readiness level on this dimension.

Regarding the "lack of support from top management" barrier, there is a clear distinction between companies with a higher and lower readiness level. The same is not true on any other category. Barriers that companies perceive to be the most important are "lack of clarification of economic benefits," "lack of standards (interoperability and compatibility)," and "underdeveloped IT infrastructures." During the interviews, other barriers that companies consider to be important were mentioned.

Company 12 is a business solutions provider through software development, which allows them to have both the company's point of view as well as the customers' point of view. The respondent from company 12 affirmed that it is necessary to invest on the implementation of I4.0 enabling technologies, but that this will not be the biggest barrier. Also believes that the biggest barrier to I4.0 implementation on companies is "underdeveloped IT infrastructures." The respondent of company 12 also adds that the vision of companies is short term and, therefore, there is no well-defined long-term strategy.
Unlike company 12, the respondent of company 5 does not consider that "underdeveloped IT infrastructures" is a very important barrier. It was mentioned that return of investment (RoI) analysis is used to understand the economic benefits. The RoI analysis makes it possible to analyze "need for large investments" and "lack of clarification of economic benefits" barriers together. Despite emphasizing the importance of "concern about data security" barrier, the respondent of company 5 does not consider it to be a very important barrier. This concern implies that employees of company 5 are not allowed to use clouds, although there is already data that is collected into a private cloud, but it is only on experimental stage. It was also mentioned by the respondent of company 5 that another barrier not specified on the questionnaire is "delay on allocation of public funds," which are a great help on I4.0 implementation regarding its enabling technologies.

The respondent of company 13 considers "lack of support from top management" barrier the most important, adding that this barrier would be equally important on any area because if there is no support from top management, it is quite difficult to introduce new concepts. Also considers "concern about data security" and "lack of regulations and procedures" as minor barriers. The respondent of company 13 affirms that there is no effective dissemination of the theme of I4.0 among potential users (companies).

The respondent of company 9 states that the concept of I4.0 is not clear and, therefore, there should be a certified entity that could perform a diagnosis helping companies on their digital transformation. This company has a clear perception of the need for innovation and the importance of constant evolution on a competitive market. The respondent of company 9 owns two other companies, one of which is being created incorporating some I4.0 enabling technologies.

\subsection{Impact of the COVID-19 pandemic}

The impact of the COVID-19 pandemic is evident around the world. Many nations are or had on lockdowns affecting all industrial tissue among other activities. All these imposed changes forced all industrial stakeholders to quickly adapt to new working conditions.

The organizations' response to COVID-19 pandemic had to be quick to its unprecedented demands, changing work practices in a short time period to train or to prepare the organizations to these new normal, new work practices where the IT technologies are the central role regarding to aspects such as behavioral, temporal, societal, and organizational [56]. According to the impact of the COVID-19 pandemic on several business sectors, Herath et al. [57] pointed out three scenarios: some organizations had to rethink their business models, some had to reduce their operations, and many were forced to close down. 


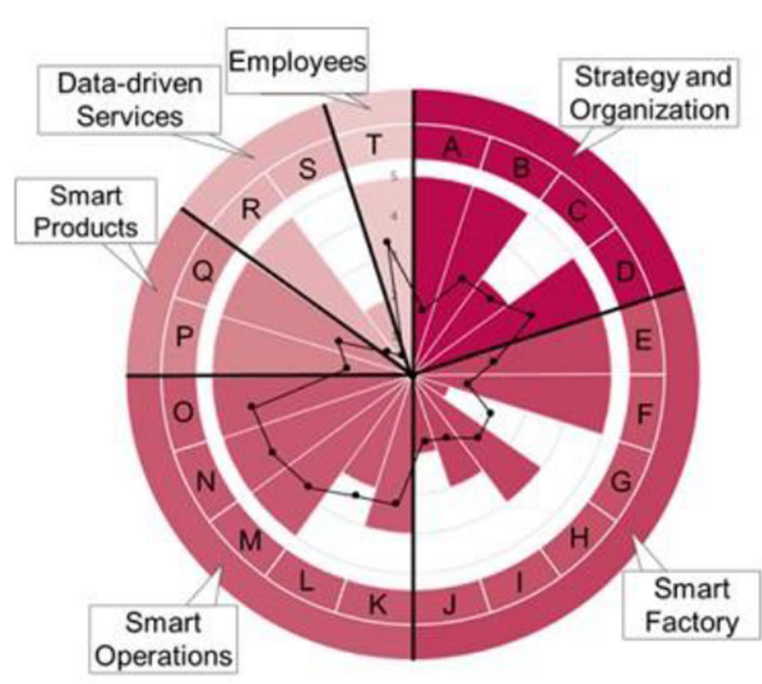

Company 12

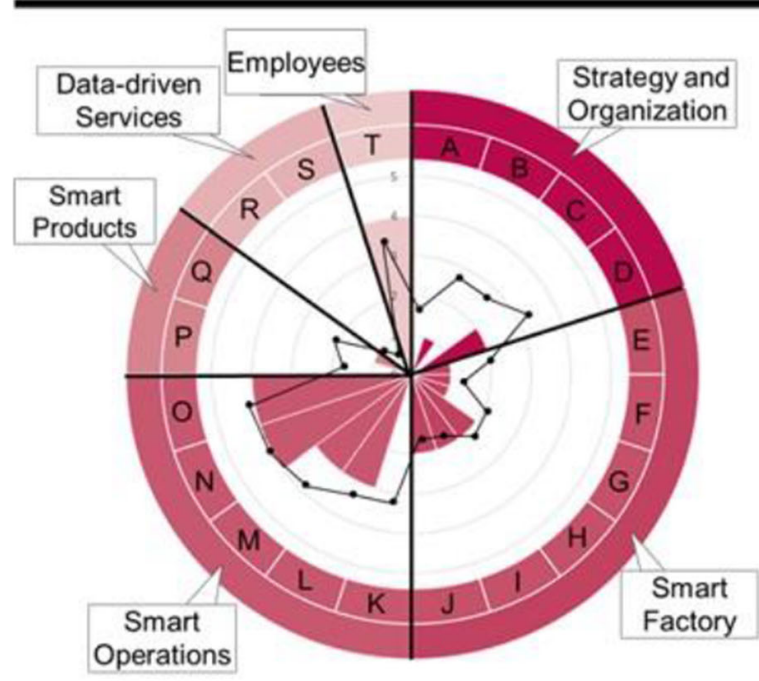

Company 13

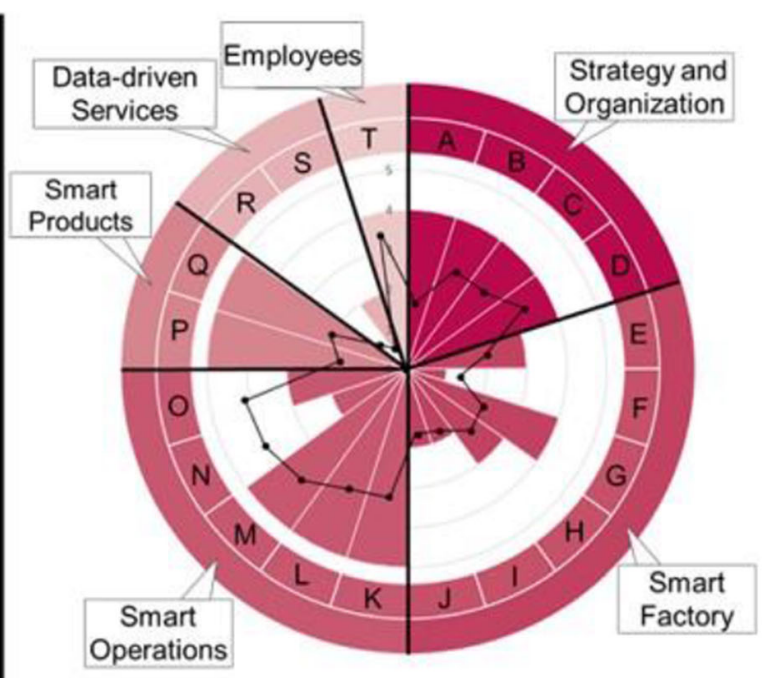

Company 5

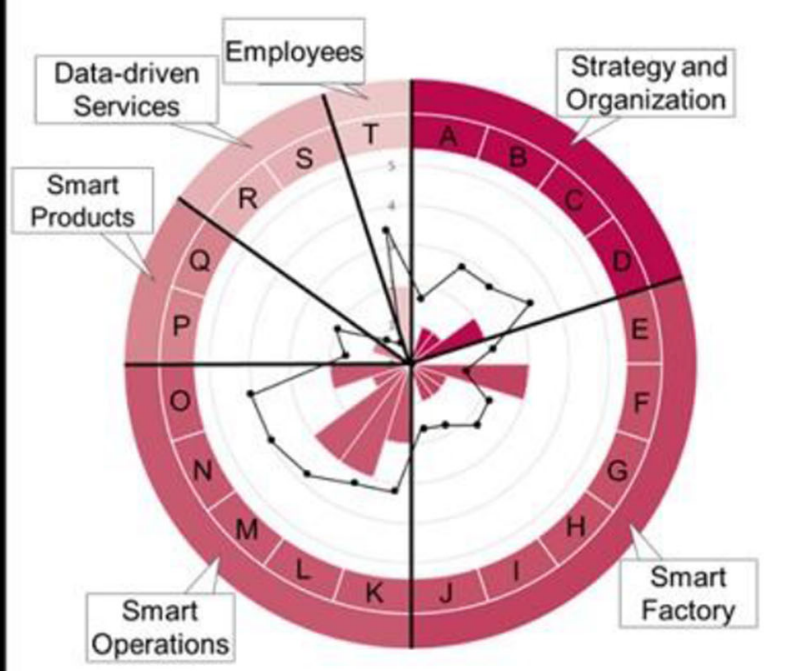

Company 9

\section{Subtitle:}

$$
\begin{aligned}
& \text { A - Degree of Strategy Implementation } \\
& \text { B - Definition of Indicators } \\
& \text { C-Investments } \\
& \text { D - Innovation Management } \\
& \text { E - Equipment Infrastructure (current) } \\
& \text { F - Equipment Infrastructure (target) } \\
& \text { G - Digital Modelling } \\
& \text { I- Data Collection } \\
& \text { J-Data Usage } \\
& \text { K-System-integrated Information Sharing }
\end{aligned}
$$

$$
\begin{aligned}
& \text { L-Autonomously Guided Workpieces } \\
& \text { M - Self-reacting Processes } \\
& \text { N - IT Security } \\
& \text { O - Cloud Usage } \\
& \text { P - ICT add-on Functionalities } \\
& \text { Q - Use of Data } \\
& \text { R - Data-driven Services } \\
& \text { S - Level of Data Usage } \\
& \text { T - Employee Skills } \\
& \text { - - - Average Readiness Level }
\end{aligned}
$$

Fig. 10 Comparison of obtained readiness levels on dimensions and its sub-dimensions for best and worst performers 
Table 12 Perception of the barrier's importance on I4.0 implementation

\begin{tabular}{|c|c|c|c|c|c|}
\hline \multirow[b]{3}{*}{ Barrier } & \multicolumn{4}{|c|}{ Company } & \multirow[b]{3}{*}{ Total } \\
\hline & \multicolumn{2}{|c|}{ High performer } & \multicolumn{2}{|c|}{ Low performer } & \\
\hline & 12 & 5 & 13 & 9 & \\
\hline Lack of clarification of economic benefits & 4 & 5 & 2 & 5 & 16 \\
\hline Lack of standards (interoperability and compatibility) & 4 & 5 & 2 & 5 & 16 \\
\hline Underdeveloped IT infrastructure & 5 & 3 & 4 & 4 & 16 \\
\hline Lack of employees' skills & 4 & 2 & 4 & 5 & 15 \\
\hline Concern with the reliability of systems & 3 & 4 & 4 & 4 & 15 \\
\hline Need for large investments & 4 & 3 & 4 & 3 & 14 \\
\hline Lack of support from top management & 2 & 2 & 5 & 5 & 14 \\
\hline Lack of technical knowledge & 4 & 2 & 4 & 4 & 14 \\
\hline Demotivation of workers & 3 & 2 & 2 & 5 & 12 \\
\hline Concern about data security & 5 & 2 & 1 & 4 & 12 \\
\hline Need to create new business models & 2 & 2 & 4 & 3 & 11 \\
\hline Lack of regulation and procedures & 4 & 2 & 1 & 3 & 10 \\
\hline
\end{tabular}

Note: Scale from 1 meaning "barrier not important" to 5 "barrier extremely important"
On the last group of this survey was included a question to understand how the current pandemic scenario has influenced companies, what is its impact on the use of I4.0 enabling technologies and how will they be used on the future.

Due to the decrease on turnover, four companies under study mention that they had to freeze or postpone planned investments. The uncertainty associated with the pandemic scenario is also a factor that led to the cancelation or postponement of new projects.

Eight companies affirmed that this pandemic has had little to no impact. The tools that allow collaborative work already existed and it was only necessary to learn how to get the best out of what was already implemented.

Company 2 , in addition to intensifying the use of communication and online meeting software, also began to develop products to support the fight against COVID-19 pandemic. The development of these products will be continuing on in accordance with the market's necessity, and company 2 is contemplating the possibility of continuing developing other products. The respondent of company 16 also claims that the pandemic had created an opportunity to develop some technologies. This company accelerated the use of analysis and remote assistance to its customers.

An interesting point is the respondent of company 17 mentioning the COVID-19 pandemic impact so far has been none. Company 17 has not stopped activity and even developed the following actions that they consider to be of a very significant relevance, as follows:

1. Fully implementation of an IT structure integrated among all resources (hybrid solution);
2. Implementation of an entirely new installation based on an integration perspective;

3. And a full-time contract of five hired new employees.

The influence and the impact of the COVID-19 pandemic on this sample is aligned with the first two scenarios pointed by Herath et al. [57]. To date of this study, no company under sample was forced to close down. On the other way, it is evident that the positive impact of COVID-19 pandemic regarding to the usage of ICT is higher than the negative impact which is described as the freezing or postpone planned investments.

\section{Discussion}

Even that some companies and its stakeholders are leading the adoption of the I4.0 enabling technologies in a certain way, the perception of the world in general related to the digital environment scenario is that this reality its very far away.

As presented in section 4, there are companies unable to relate the I4.0 with their business models, and there are companies who do not have a clear vision of I4.0 and how they can take advantages of this digital environment. This leads to a lack of I4.0 strategy with clear goals to short term, without measures to get benefits to companies. Nevertheless, there are companies with I4.0 pilot projects trying to understand the benefits and to extract the best of the I4.0 enabling technologies for their business models. Although, it is missing the needed skills to perform the correct capacity' assessment related to the adoption of the I4.0 enabling technologies as a 
whole and the needed strength to stimulate collaborators to embrace this new digital environment.

The usage of data, its collection, and its sharing to further analyze and use on decision-making on product and process improvement and also on connections with all the value chain is poor. It is clear that most of companies are taking a defensive stance with fear of investments and waiting for the evolution of its competitors and its business partners.

The literature brings some qualitative studies using IMPULS model. Silva and Rocha [42] used IMPULS model to study a Brazilian strategic defense company. Hamidi et al. [43] studied Malaysian SMEs from various industries showing IMPULS dimensions average levels. Maasz et al. [44] studied one South African company in the mining industry.

Lichtblau et al. [7] present a full study, both qualitative and quantitative in two German activity areas such as mechanical and pant engineering (sample of 234 respondents) and manufacturing (sample of 602 respondents), having 0.9 and 0.6 average readiness scores, respectively.

This study presents a wider sample regarding the activity area with an average readiness score of 1.74 . It is higher from readiness scores of Lichtblau et al. [7] but the characteristics of the samples are different.

Looking forward on the understanding of the poor readiness level of this sample, the perception of the I4.0 enabling technologies adoption barriers that were extracted from the semi-structured questionnaire retrieves useful insights. The most important perceptions of the highlighted barriers were "lack of clarification of economic benefits," "lack of standards (interoperability and compatibility)," and "underdeveloped IT infrastructure."

The "lack of clarification of economic benefits" barrier can show that companies do not have a clear vision on I4.0 environments and this lack of vision and company strategy to face the near future starts on the top management.

The "lack of standards (interoperability and compatibility)" barrier can show that companies do not have the needed working skills on their working groups to prepare the digital environment.

The "underdeveloped IT infrastructure" barrier can show that companies are not as proactive and do not have a long-term vision. Most companies depend on public funds to innovate in products, processes, or even on their facilities. This dependence is harmful and, as company 5 respondent mentions, the delay on public funds leads to the cancelation of innovation initiatives. Using relevant studies regarding the I4.0 barriers [11-17], on the interviews regarding the perception of the importance of the barriers, brought to discussion new barriers as "delay on allocation of public funds" and "lack of a certified entity to perform a I4.0 diagnosis."

\section{Conclusions}

Some experts estimate that the progress of I4.0 will boost the industry allowing to meet the increasingly demanding requirements of its customers and thus preserve its competitive advantage [19]. Despite the advantages associated with its implementation, companies may not use as many technologies as there are some barriers that hinder their implementation.

Through "Mapping the Adoption of Technologies for Industry 4.0 on Setúbal Peninsula" survey, it was possible to conclude that the responding companies have an average readiness level of 1.74 , with the most frequently attributed readiness level 1. A company inserted on this readiness level is part of "newcomers" category and it is considered that it is involved on I4.0 through pilot initiatives on several departments, has investments on a single area, and IT security solutions are still on the planning or implementation phase.

With the assessment of what is the perception of the barriers' importance to implement I4.0 with semi-structured interviews, it was possible to understand what the most important barriers from the companies' perspective. It was concluded that the barriers considered most important were as follows: "lack of clarification of economic benefits," "lack of standards (interoperability and compatibility)," and "underdeveloped IT infrastructure." The linkage of these barriers to the surveyed readiness levels leads to the understanding of companies without a vision and a strategy to face the near future starting on the top management. These perceptions on the barriers' importance also leads to lack of proactive and long-term vision. It was also perceived that most companies depend on public funds to innovation initiatives.

The surveyed question related to the impact of the COVID19 pandemic shows that more than half of the companies in the sample, $53.3 \%$ affirm that the necessary tools for working remotely already existed, being only necessary to learn how to make the best of them. On the opposite direction, four companies reported that the pandemic scenario has negatively affected their turnover, which has led to a freeze on I4.0 investments. Only one company claims that they were not affected, and all previously planned actions were implemented. One of the companies started to use communication software for remote working more often and claims that changed its production in order to develop products to support the fight against COVID-19 pandemic.

As a recommendation for future research, a new assessment of companies' readiness level is suggested to evaluate the impact of the COVID-19 pandemic on I4.0 enabling technologies adoption. On the one hand, companies may have postponed the implementation of some I4.0 enabling technologies due to lack of financial resources, human resources, or even lack of time. On the other hand, companies may have been driven to consider new ways of manufacturing with less human resources 
due to the increase on remote work. Knowing that the most affected companies by this crisis associated with the COVID-19 pandemic are SMEs [58] and that $66.7 \%$ of respondents on this study belong to this category, it would be interesting to see if this trend is verified with these companies and understand its impact.

Some AISET member companies operate together, forming value chains and creating synergies with each other. An opportunity created through the partnership with AISET would be to compare the readiness levels between the companies involved in the same value chain. It was not possible to achieve this goal because AISET member companies that were available to be surveyed unfortunately do not form value chains.

One of the mentioned barriers by the surveyed companies is the "lack of clarification of economic benefits" and some add that they would be interested in being assessed in this area by an accredited entity. On this way, it would be beneficial to conduct a study on the added value, not only economic but also competitive, of I4.0 enabling technologies adoption.

Acknowledgements Special thanks to AISET for this good partnership, to Freepik for providing vectors/icons for some figures, available at www. flaticon.com, and to all reviewers for their valuable feedback.

Author contribution Vítor Alcácer designed and coordinated this study, Carolina Rodrigues drafted the manuscript, Helena Carvalho revised the manuscript, and Virgílio Cruz-Machado supervised the project and the manuscript. All authors read and approved the manuscript.

Funding This research was funded by Fundação para a Ciência e Tecnologia (FCT-MCTES) via the project UIDB/00667/2020 (UNIDEMI).

Data availability All datasets and datasheets used to support the discussion and conclusions on this study are available upon request to the corresponding author.

\section{Declarations}

Ethical approval All surveyed participants have given their consents to participate on this study under the General Data Protection Regulation (GDPR).

Consent to participate All surveyed participants have agreed on participating and they have understood the aim of the project. All participants have given their consents to use surveyed data on this study on an anonymous manner. All surveyed participants as protected under the General Data Protection Regulation (GDPR).

Consent to publish All authors give their consent for the publication of the manuscript, which include all its details such as figures, tables, or all relevant information to be published on The International Journal of Advanced Manufacturing Technology.

Competing interests The authors declare no competing interests.

\section{References}

1. Hofmann E, Rüsch M (2017) Industry 4.0 and the current status as well as future prospects on logistics. Comput Ind 89:23-34. https:// doi.org/10.1016/j.compind.2017.04.002

2. Zhou K, Lui T, Zhou L (2015) Industry 4.0: towards future industrial opportunities and challenges. In: 2015 12th International Conference on Fuzzy Systems and Knowledge Discovery (FSKD), pp 2147-2152. https://doi.org/10.1109/FSKD.2015. 7382284

3. Zhou J, Li P, Zhou Y, Wang B, Zang J, Meng L (2018) Toward new-generation intelligent manufacturing. Engineering 4:11-20. https://doi.org/10.1016/j.eng.2018.01.002

4. Xu L, Xu E, Li L (2018) Industry 4.0: state of the art and future trends. Int J Prod Res 56:2941-2962. https://doi.org/10.1080/ 00207543.2018.1444806

5. Roblek V, Meško M, Krapež A (2016) A complex view of industry 4.0. SAGE Open 6, p 215824401665398. https://doi.org/10.1177/ 2158244016653987

6. Schumacher A, Erol S, Sihn W (2016) A maturity model for assessing industry 4.0 readiness and maturity of manufacturing enterprises. Procedia CIRP 52:161-166. https://doi.org/10.1016/j. procir.2016.07.040

7. Lichtblau $\mathrm{K}$ et al. (2015) Industrie 4.0 Readinessr. http:// industrie40.vdma.org/documents/4214230/5356229/Industriel\% 204.0 $\ \% 20$ Readiness $\backslash \% 20$ Study $\backslash \% 20$ English.pdf/f6de92c1-74ed4790-b6a4-74b30b1e83f0. Accessed 15 September 2020

8. Schuh G, Anderl R, Gausemeier J, Wahlster W (2017) Industrie 4.0 maturity index - managing the digital transformation of companies, acatech - National Academy of Science and Engineering. https://en. acatech.de/publication/industrie-4-0-maturity-index-managing-thedigital-transformation-of-companies/. Accessed 15 September 2020

9. Rockwell Automation (2014) The connected enterprise maturity model (2014). https://iterature.rockwellautomation.com/idc/ groups/literature/documents/wp/cie-wp002 _-en-p.pdf. Accessed 16 September 2020

10. Jung K, Kulvatunyou B, Choi S, Brundage MP (2017) An overview of a smart manufacturing system readiness assessment. advances in production management systems. Initiat Sustain World 488:705-712. https://doi.org/10.1007/978-3-319-51133-7\_83

11. World Economic Forum (2015) Industrial Internet of Things: unleashing the potential of connected products and services. https://www.weforum.org/press/2015/01/industrial-internet-ofthings-unleashing-the-potential-of-connected-products-andservices/. Accessed 02 October 2020

12. Müller JM, Buliga O, Voigt K-I (2018) Fortune favors the prepared: how SMEs approach business model innovations in industry 4.0 . Technol Forecast Soc Chang 132:2-17. https://doi.org/10.1016/j. techfore.2017.12.019

13. Stentoft J, Jensen KW, Philipsen K, Haug A (2019) Drivers and barriers for industry 4.0 readiness and practice: a SME perspective with empirical evidence. Proceedings of the 52nd Hawaii International Conference on System Sciences, United States 5155-5164. https://doi.org/10.24251/hicss.2019.619

14. Müller J, Maier L, Veile J, Voigt K-I (2017) Cooperation strategies among SMEs for implementing industry 4.0. Proceedings of the Hamburg International Conference of Logistics (HICL) 301-318. https://doi.org/10.15480/882.1462

15. Li S, Xu LD, Zhao S (2015) The internet of things: a survey. Inf Syst Front 17:243-259. https://doi.org/10.1007/s10796014-9492-7

16. Beqqal ME, Azizi M (2017) Classification of major security attacks against RFID systems. 2017 International Conference on Wireless 
Technologies, Embedded and Intelligent Systems (WITS) 1-6. https://doi.org/10.1109/WITS.2017.7934622

17. Yang C, Huang Q, Li Z, Liu K, Hu F (2017) Big Data and cloud computing: innovation opportunities and challenges. Int J Digital Earth 10:13-53. https://doi.org/10.1080/17538947.2016.1239771

18. Alcácer V, Cruz-Machado V (2019) Scanning the industry 4.0: a literature review on technologies for manufacturing systems. Eng Sci Technol Int J 22:899-919. https://doi.org/10.1016/j.jestch. 2019.01.006

19. Oztemel E, Gursev S (2020) Literature review of industry 4.0 and related technologies. J Intell Manuf 31:127-182. https://doi.org/10. 1007/s10845-018-1433-8

20. Michelsen KE (2020) Industry 4.0 in retrospect and in context. In: Collan M, Michelsen KE (eds) Technical, economic and societal effects of manufacturing 4.0. Palgrave Macmillan, Cham. https:// doi.org/10.1007/978-3-030-46103-4\1

21. Lu Y (2017) Industry 4.0: a survey on technologies, applications and open research issues. J Ind Inf Integr 6:1-10. https://doi.org/10. 1016/j.jii.2017.04.005

22. Leyh C, Martin S, Schäffer T (2017) Industry 4.0 and lean production - a matching relationship? An analysis of selected industry 4.0 models. Ann Comp Sci Inform Syst 11:989-993 https://annals-csis. org/proceedings $/ 2017 / \mathrm{drp} / 365 . \mathrm{htm}$

23. Baena F, Guarin A, Mora J, Sauza J, Retat S (2017) Learning factory: the path to industry 4.0. Procedia Manuf 9:73-80. https:// doi.org/10.1016/j.promfg.2017.04.022

24. Weyer S, Schmitt M, Ohmer M, Gorecky D (2015) Towards industry 4.0 - standardization as the crucial challenge for highly modular, multi-vendor production systems. IFAC-PapersOnLine 48:579584. https://doi.org/10.1016/j.ifacol.2015.06.143

25. Peruzzini M, Grandi F, Pellicciari M (2017) Benchmarking of tools for user experience analysis in industry 4.0. Procedia Manuf 11: 806-813. https://doi.org/10.1016/j.promfg.2017.07.182

26. Motyl B, Baronio G, Uberti S, Speranza D, Filippi S (2017) How will change the future engineers' skills in the industry 4.0 framework? A questionnaire survey. Procedia Manuf 11:1501-1509. https://doi.org/10.1016/j.promfg.2017.07.282

27. Grieco A, Caricato P, Gianfreda D, Pesce M, Rigon V, Tregnaghi L, Voglino A (2017) An industry 4.0 case study in fashion manufacturing. Procedia Manuf 11:871-877. https://doi.org/10. 1016/j.promfg.2017.07.190

28. Wagner T, Herrmann C, Thiede S (2017) Industry 4.0 impacts on lean production systems. Procedia CIRP 63:125-131. https://doi. org/10.1016/j.procir.2017.02.041

29. Jiang J (2017) An improved Cyber-Physical Systems architecture for Industry 4.0 smart factories. In: 2017 International Conference on Applied System Innovation (ICASI), pp 918-920. https://doi. org/10.1109/ICASI.2017.7988589

30. Gilchrist A (2016) In: Gilchrist A (ed) Smart Factories. Industry 4.0: The industrial Internet of Things. Apress, Berkeley, pp 217-230

31. Pérez F, Irisarri E, Orive D, Marcos M, Estevez E (2015) A CPPS architecture approach for industry 4.0. 2015 IEEE 20th Conference on Emerging Technologies Factory Automation (ETFA) 1-4. https://doi.org/10.1109/ETFA.2015.7301606

32. Liu $\mathrm{Y}, \mathrm{Xu} X$ (2016) Industry 4.0 and cloud manufacturing: a comparative analysis. J Manuf Sci Eng 139:034701. https://doi.org/10. $1115 / 1.4034667$

33. Canetta L, Barni A, Montini E (2018) Development of a digitalization maturity model for the manufacturing sector. 2018 IEEE International Conference on Engineering, Technology and Innovation (ICE/ITMC) 1-7. https://doi.org/10.1109/ICE.2018. 8436292

34. Mettler T (2009) A design science research perspective on maturity models in information systems. Institute of Information
Management, Universtiy of St. Gallen. https://www.alexandria. unisg.ch/214531/

35. De Carolis A, Macchi M, Negri E, Terzi S (2017) A maturity model for assessing the digital readiness of manufacturing companies. In: Advances in production management systems. The path to intelligent, collaborative and sustainable manufacturing, Cham, pp 1320. https://doi.org/10.1007/978-3-319-66923-6\2

36. Stefan L, Thom W, Dominik L, Dieter K, Bernd K (2018) Concept for an evolutionary maturity based Industrie $4.0 \mathrm{mi}-$ gration model. Procedia CIRP 72:404-409. https://doi.org/10. 1016/j.procir.2018.03.155

37. Rajnai Z, Kocsis I (2018) Assessing industry 4.0 readiness of enterprises. 2018 IEEE 16th World Symposium on Applied Machine Intelligence and Informatics (SAMI) 225-230. https://doi.org/10. 1109/SAMI.2018.8324844

38. Gernandt J, Röger S (n.d.) Industrie 4.0 readiness check, IMPULS readiness check. https://www.industrie40-readiness.de/?sid= 62931\&lang=en. Accessed 23 October 2020

39. Lopes E (2017) Indústria 4.0: Programa de melhorias em centros de maquinagem numa indústria metalomecânica. Dissertation, Universidade do Porto, Portugal

40. Rodrigues J (2020) Análise de um Sistema Produtivo Orientado para os Requisitos da Indústria 4.0: Caso de Estudo Visteon Palmela. Dissertation, Universidade Nova de Lisboa, Portugal

41. Agostinho P (2019) A Auditoria Interna no desenvolvimento da Indústria 4.0 em Portugal. Dissertation, Instituto Superior de Contabilidade e Administração de Lisboa, Portugal

42. Silva M, Rocha C (2020) Assessment of industry maturity level 4.0: the case of a strategic defense company. Future Stud Res J Trends Strat 12:31-59. https://doi.org/10.24023/FutureJournal/2175-5825/ 2020.v12i1.455

43. Hamidi SR, Aziz AA, Shuhidan SM, Aziz AA, Mokhsin M (2018) SMEs maturity model assessment of IR4.0 digital transformation. In: Proceedings of the 7th International Conference on Kansei Engineering and Emotion Research, pp 721-732. https://doi.org/ $10.1007 / 978-981-10-8612-0 \backslash 75$

44. Maasz GJ, H. Darwish H (2018) Towards an initiative-based industry 4.0 maturity improvement process: master drilling as a case study. S Afr J Industr Eng 29:92-107. https://doi.org/10.7166/293-2052

45. Türkes MC, Oncioiu I, Aslam HD, Marin-Pantelescu A, Topor DI, Căpuşneanu S (2019) Drivers and barriers in using industry 4.0: a perspective of SMEs in Romania. Processes 7:153. https://doi.org/ 10.3390/pr7030153

46. Orzes G, Rauch E, Bednar S, Poklemba R (2018) Industry 4.0 implementation barriers in small and medium sized enterprises: a focus group study. In: 2018 IEEE International Conference on Industrial Engineering and Engineering Management (IEEM), pp 1348-1352. https://doi.org/10.1109/IEEM.2018.8607477

47. Groves RM, Jr Fowler JF, Couper MP, Lepkowski JM, Singer E, Tourangeau R (2011) Survey methodology, 2nd edn. John Wiley \& Sons

48. INFORMA $\mathrm{D} \backslash \&$ B, Directorio Empresas Portugal (n.d.) Informação comercial, Guia de Empresas de Portugal, Directório de todas as empresas em Portugal. https://infoempresas.jn.pt. Accessed 01 November 2020

49. Associação da Indústria da Península de Setúbal (AISET) (2020) AISET. https://aiset.pt/. Accessed 30 October 2020

50. Leeuw ED, Hox JI, Dillman DA (2008) International handbook of survey methodology. Taylor \& Francis Group/Lawrence Erlbaum Associates, New York

51. Ponto J (2015) Understanding and evaluating survey research. J Adv Practit Oncol 6:168-171. https://doi.org/10.6004/jadpro. 2015.6.2.9 
52. UNIDEMI (Departamento de Engenharia Mecânica e Industrial) (n.d.) Driving I4.0. http://www.unidemi.com/research/projects/ driving-i4.0/. Accessed 01 November 2020

53. Al-Qurtas M, Zairi M (2003) Enhancement of the effectiveness of case studies as a research method through the selection of polar cases. J Adv Manag Res 1:41-47. https://doi.org/10.1108/ 97279810380000357

54. Eisenhardt KM, Graebner ME (2007) Theory building from cases: opportunities and challenges. Acad Manag J 50:25-32. https://doi. org/10.5465/amj.2007.24160888

55. Eisenhardt KM (1989) Building theories from case study research. Acad Manag Rev 14:532-550. https://doi.org/10.2307/258557

56. Carrol N, Conboy K (2020) Normalising the "new normal": changing tech-driven work practices under pandemic time pressure. Int J Inf Manag 55:102186. https://doi.org/10.1016/j.ijinfomgt.2020. 102186
57. Herath T, Herath $\mathrm{H}$ (2020) Coping with the new normal imposed by the COVID-19 pandemic: lessons for technology management and governance. Inf Syst Manag 37:277-283. https://doi.org/10.1080/ 10580530.2020.1818902

58. Dimson J, Mladenov Z, Sharma R, Tadjeddine K (2020) COVID19 and European small and medium-size enterprises: how they are weathering the storm. McKinsey Global Publishing. https://www. mckinsey.com/industries/public-and-social-sector/our-insights/ covid-19-and-european-small-and-medium-size-enterprises-howthey-are-weathering-the-storm. Accessed 13 November 2020

Publisher's note Springer Nature remains neutral with regard to jurisdictional claims in published maps and institutional affiliations. 